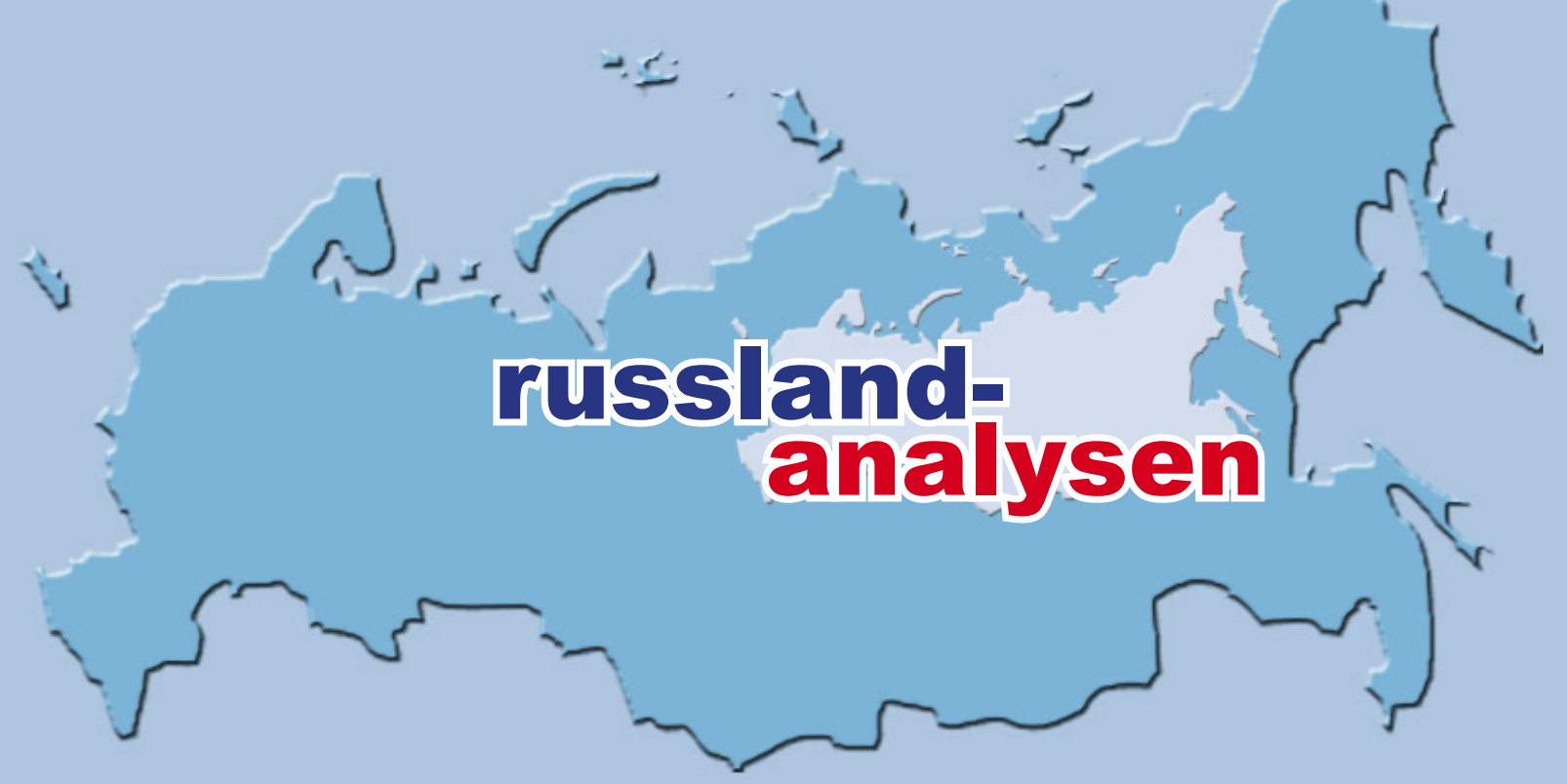

\title{
MIGRATIONSPOLITIK IN RUSSLAND
}

ANALYSE

Zwischen Liberalisierung und Restriktion: Entwicklungen der russischen Migrationspolitik Matthew Light, Toronto

http://www.laender-analysen.de/russland/

ANALYSE

One way ticket oder vorübergehende Zuflucht? Flüchtlinge aus der Ukraine in Russland Irina Kuznetsova, Birmingham

ANALYSE

Wer kommt? Die aktuelle Entwicklung des Zuwanderungsmanagements Russlands Olga Gulina, Berlin / Moskau

- UMFRAGE

Immigration nach Russland $\quad 19$

$\begin{array}{lr}\text { Emigration aus Russland } & 22\end{array}$

$\begin{array}{lr}\text { Flüchtlingssituation in Europa und Russland } & 23\end{array}$

\begin{tabular}{ll} 
Krieg in der Ostukraine & 24 \\
\hline
\end{tabular}

NOTIZEN AUS MOSKAU

Isaaks-Kathedrale

Jens Siegert, Moskau

AUS RUSSISCHEN BLOGS

„Überläufer«. Zwei ehemalige Duma-Abgeordnete finden Zuflucht in der Ukraine

Sergey Medvedev, Berlin

CHRONIK

17. Februar - 2. März 2017 


\title{
Zwischen Liberalisierung und Restriktion: Entwicklungen der russischen Migrationspolitik
}

\author{
Matthew Light, Toronto
}

\section{Zusammenfassung}

Obwohl die Russische Föderation von Vielen im Westen als ein Emigrationsland wahrgenommen wird, hat es seit der Unabhängigkeit 1991 eine beträchtliche Immigration nach Russland gegeben, meist aus anderen ehemaligen Sowjetrepubliken. Darüber hinaus hat das Land auch eine erhebliche Binnenmigration erfahren. Diese Migrationsprozesse haben die Größe und die ethnische Zusammensetzung der Bevölkerung Russlands sowie deren Verteilung über die Regionen verändert. Die Politik zur Steuerung der Migration hat sich von dem äußerst strikt reglementierten System der Sowjetunion fortbewegt, ohne eine vollkommene Liberalisierung zu erreichen. Dieser Beitrag untersucht die Gründe für diese Entwicklung der Migrationspolitik, unter anderem die Weigerung des russischen Staates, Migrationsrechte voll durchzusetzen, die Unterordnung der Migrationspolitik unter geopolitische Ziele und die rhetorische Festlegung auf einen ethnisch russischen Nationalismus. Der jüngste politische Wandel deutet auf eine Bewegung hin zu einer größeren Steuerung der Auswanderung russischer Staatsangehöriger und der Annahme anderer Staatsangehörigkeiten. Darüber hinaus verknüpft die staatliche Politik Migrationsrechte mit einer politischen und wirtschaftlichen Integration zwischen Russland und anderen postsowjetischen Staaten.

\section{Steuerung internationaler Migration in der Sowjetunion}

Die Migrationsprozesse in der Sowjetunion (1917-1991) sind auf ganz andere Weise gesteuert worden als seinerzeit in den kapitalistischen Staaten des Westens, seien sie nun autoritär oder demokratisch verfasst gewesen. Die Sowjetunion war bereits ganz früh bestrebt, den Bevölkerungsaustausch mit der Außenwelt zu beschränken, sowohl in Bezug auf Emigration, als auch - was im Westen weniger bekannt ist - auf Immigration. Seit den ausgehenden 1920er Jahren bis zu den letzten Jahren der Sowjetherrschaft hat es erhebliche Restriktionen für eine Ausreise gegeben; eine Ausreise war mehr ein Privileg als ein Recht. Hauptzweck dieser Politik war es, ungenehmigte Emigration zu verhindern. Das wiederum spiegelte die stillschweigende Erkenntnis der Sowjetregierung wieder, dass viele Sowjetbürger gehen könnten, wenn sie die Gelegenheit dazu bekämen, weil das Leben in der UdSSR äußerst stark reglementiert war, es keine Möglichkeit gab, sich in der Zivilgesellschaft frei zusammenzuschließen, die politische Mitwirkung erheblich beschränkt war und der Lebensstandard niedriger als in den nichtkommunistischen Gesellschaften Europas sowie von ernsthaften Versorgungsschwierigkeiten bei Konsumgütern und von materiellen Härten geprägt war. Ausnahmen vom Emigrationsverbot gab es nur bei vereinzelten Dissidenten (etwa bei Solschenizyn), und bei einigen Angehörigen bestimmter ethnischer Gruppen mit Verbindungen zu anderen Staaten, die deren Umsiedlung ausgehandelt hatten (Deutsche und Juden). In einer späteren Phase der sowjetischen Geschichte wurde es Bürgern, denen man traute, erlaubt, das Land aufZeit zu verlassen, z. B. als Tourist. Doch die wurden dann gründlich geprüft und durften gewöhnlich nur in Gruppen reisen. Wie diese Beschränkungen bei Auslandsreisen sollte auch der nahezu totale Bann auf Immigration in die UdSSR die ideologische Konformität fördern. Der Sowjetstaat wollte verhindern, dass seine Bürger Informationen von Ausländern erhielten, sei es über das Leben im Ausland oder über die Sowjetunion selbst. Zur Beschränkung des Informationsflusses, und um sicherzustellen, dass alle Sowjetbürger loyal zum Regime sind, war die Regierung bereit, auf die Vorteile einer zahlenstarken Immigration zu verzichten, selbst in der Nachkriegszeit, als das Land verwüstet war und von einem Zustrom von Gastarbeitern (wie dem in die BRD) profitiert haben könnte. Die Sowjetunion hat nie eine Politik verfolgt, die eine routinehafte Immigration von ausländischen Staatsangehörigen erlaubt hätte.

\section{Regulierung von Mobilität in der Sowjetunion}

Auch die innersowjetische Migrationspolitik unterschied sich im internationalen Vergleich. Wie viele andere europäische Gesellschaften damals und jetzt auch, verlangte die UdSSR eine Registrierung des Wohnsitzes ihrer Bürger. Anders als in liberalen kapitalistischen Gesellschaften diente das Meldeverfahren nicht der Information, sondern erforderte eine Genehmigung. In der Praxis setzte der Staat die Steuerung der Binnenmigration zu mehreren Zwecken ein. Zum einen lenkten die Behörden damit Arbeiter in jene Regionen und Unternehmen, in denen sie gebraucht wurden; sie begrenzten und steuerten die Abwanderung von Bauern, die in 
den Kolchosen gebraucht wurden, in die Städte; und sie beschränkten die Migration nach Moskau und in bestimmte andere Städte, die besser mit knappen Gütern oder Dienstleistungen versorgt waren. Ein zusätzlicher Grund für eine Steuerung der Binnenmigration war die Kontrolle über unliebsame Bürger, etwa über Angehörige bestimmter ethnischer Minderheiten (zu denen wiederum die Wolgadeutschen gehörten) oder über politisch unzuverlässige Individuen. Schlüsseldokumente für die Handhabung der Binnenmigration waren der sogenannte "Inlandspass" und die propiska (Wohnsitzgenehmigung).

Die sowjetische Migrationspolitik war zwar in vielerlei Hinsicht repressiv, bestand aber nicht ausschließlich aus Verboten. Der sowjetische Staat förderte Binnenmigration durch die Entwicklung von Infrastruktur und Beschäftigung sowie subventionierte Reisen und andere Formen von Sozialleistungen, die über den Arbeitsplatz erteilt wurden. Der sowjetische Staat überwachte die Transformation des Landes von einer mehrheitlich ländlichen Gesellschaft zu einer überwiegend städtischen und industrialisierten. Er stimulierte darüber hinaus Migrationsprozesse, durch die viele Teile des Landes in größerem Maße multiethnisch wurden, beispielsweise, indem Bürger aus dem europäischen Teil des Landes zur Ansiedlung in Sibirien und Zentralasien bewegt wurden. Rückblickend besteht der beste Ansatz zu einem Verständnis der sowjetischen Migrationspolitik in der Erkenntnis, dass sie auf etwas ausgerichtet war, dass ich als »Folgsamkeit gegenüber dem Regime« bezeichnet habe, und zwar durch Schaffung einer bestimmten Art Sowjetbürger, die sich in voller Harmonie mit den Bedürfnissen des politischen Systems und den Ansprüchen des Regimes befindet.

\section{Neue Migrationsmuster im postsowjetischen Russland}

In einigen meiner Veröffentlichungen habe ich die Änderungen in den Migrationsmustern und der jeweiligen Politik im frühen postsowjetischen Russland skizziert und analysiert. Zum einen öffnete die Abschaffung der sowjetischen Restriktionen für Auslandsreisen (eine Politik, die in der Verfassung von 1993 und nachfolgenden Gesetzen verankert wurde) bekanntermaßen die Schleusen für eine ständige oder aber vorübergehende Ausreise von Bürgern Russlands. Neben den »DiasporaMinderheiten« sind Bürger mit unterschiedlichstem ethnischen oder sozialem Hintergrund in großen Zahlen emigriert. Viele andere, die ihren Hauptwohnsitz in Russland beibehielten, haben sich an ungehinderte Auslandsreisen zu geschäftlichen oder persönlichen Zwecken (einschließlich Tourismus) gewöhnt. Nach einer anfänglichen Welle während der Krisenjahre Anfang der
1990 er ging die Emigration in den 2000 er Jahren erheblich zurück, hat aber in letzter Zeit wieder zugenommen, vor allem durch Fachkräfte und aus einer Mischung aus wirtschaftlichen und politischen Motiven, unter anderem wegen einer Unzufriedenheit mit Russlands politischer und wirtschaftlicher Entwicklungsbahn.

Zweitens ist Russland, und das ist weniger bekannt, jetzt das Zentrum eines der weltweit größten internationalen Migrationsnetzwerke. Dabei hat in der postsowjetischen Zeit Immigration beharrlich die Emigration überwogen und angesichts der niedrigen Geburtszahlen und der hohen Sterblichkeit in Russland ist es die wichtigste (und bisweilen einzige) Quelle für Bevölkerungswachstum gewesen. Trotz einer Zunahme der Immigration aus einigen asiatischen Ländern erfolgt der größte Teil der Immigration nach Russland aus anderen postsowjetischen Staaten. Viele Autoren unterscheiden zwei Phasen postsowjetischer Immigration nach Russland. Die erste Phase fiel grob betrachtet mit den 1990er Jahren zusammen, als diese Art Immigration zum größten Teil durch politische Wirren und ethnische Konflikte in anderen Teilen der ehemaligen UdSSR verursacht wurde und einen erheblichen Anteil ethnischer Russen aufwies, die nach Russland umsiedeln wollten. In der zweiten Phase, ungefähr nach der Jahrtausendwende, wurde die politisch motivierte dauerhafte Umsiedlung zu großen Teilen von vorübergehender Arbeitsmigration abgelöst, nun vor allem aus Zentralasien. Die meisten Beobachter sind der Ansicht, dass eine weitere Immigration ethnischer Russen aus anderen postsowjetischen Staaten wohl kaum in großem Umfang stattfinden wird. Angenommen wird auch, dass "nichteuropäische« Immigration (aus Zentralasien und in der Zukunft vielleicht zunehmend von außerhalb der ehemaligen UdSSR) ein permanentes Phänomen sein werde, auf das mit einer staatlichen Politik zur erleichterten Erlangung eines ständigen Wohnsitzes oder der Staatsbürgerschaft reagiert werden muss, und das das Entstehen einer stärker multikulturellen Gesellschaft erfordert.

\section{Regionale Unterschiede}

Die rechtlichen Änderungen der postsowjetischen Zeit haben auch den regulatorischen - lies: restriktiven Charakter der Wohnsitzregistrierung formal abgeschafft. Bürger Russlands und ausländische Staatsangehörige, die sich legal in Russland aufhalten, haben nun theoretisch das umfassende Recht, sich im Land zu bewegen, zu übernachten und Besuche zu unternehmen, wo sie wollen. Dieser Politikwechsel hat in Kombination mit der Privatisierung staatlicher Unternehmen und dem Ende der meisten Subventionen der Sowjetzeit zu einem massiven Anwachsen Moskaus geführt und (zusammen mit internationaler Migration) der Stadt und eini- 
gen anderen Teilen von Russland einen sehr viel stärker multikulturellen Charakter verliehen; die Konzentration ethnischer Gruppen aus Zentralasien und dem Kaukasus ist nun viel größer als zu Sowjetzeiten. Als logische Folge haben Moskau und einige andere Städte nun einen viel größeren Anteil von Einwohnern, die zumindest formal muslimisch sind. Anderenorts haben diese Tendenzen zu einer Umkehr der sowjetischen Bevölkerungsentwicklung geführt, etwa in Sibirien und dem Hohen Norden Russlands, die beide eine beträchtliche Abwanderung ihrer Bevölkerung erlebt haben.

Wenn auch Russlands Migrationspolitik zweifellos liberalisiert wurde, indem sie nicht mehr dermaßen reglementiert und restriktiv war, so war sie dennoch davon entfernt als liberale Migrationspolitik bezeichnet zu werden. Wie erwähnt, bestand für die Bewegungsfreiheit der Bürger Russlands der größte Gewinn darin, dass die Restriktionen bei der Ausreise wegfielen, was zumindest bis vor kurzem in der Praxis wie auch formal Bestand hatte. Bei der Binnenmigration wie auch bei der Immigration ist die Lage weniger eindeutig. Ich habe darauf hingewiesen, dass die Regionalregierungen in Russland de facto - und von der Zentralregierung toleriert - eine vielfältige, restriktive Politik betreiben, durch die die tatsächliche Freizügigkeit sowohl von Ausländern als auch von Bürgern Russlands eingeschränkt wird. Die Motive für eine derartige Politik sind erneut teils wirtschaftlicher, teils (in mehrfacher Hinsicht) politischer Natur. Einige florierende Regionen - vor allem Moskau - haben versucht, die Registrierung neuer Residenten (und somit deren politische, soziale und sogar deren Vertragsrechte) zu beschränken, selbst wenn es sich um Bürger Russlands handelt. Das erfolgte zum Teil aus fiskalischen Überlegungen heraus: In Russland besteht zwischen den Regionen ein Ungleichgewicht bei öffentlichen Leistungen, und Transferzahlungen aus dem Zentralhaushalt reichen nicht aus, die Kosten hierfür vollständig abzudecken, insbesondere in wohlhabenderen Regionen. Manchmal gibt es ethnische Motive für solche Restriktionen. Moskau und einige andere Regionen haben sich geweigert Angehörigen bestimmter ethnischer Gruppen einen Aufenthaltsstatus zu gewähren, vor allem jenen aus dem Kaukasus und insbesondere Tschetschenen. Und schließlich geht es bei der Einschränkung der Registrierung einfach darum, die Subjekte einer Kontrolle zu unterstellen. Wenn Niederlassungsrechte beschnitten werden können, wird die Lage einer Person (sei sie ein Ausländer oder ein Bürger Russlands) angreifbarer und erhöht auf allen Ebenen die Macht des Staates über ihn oder sie. Darüber hinaus fördert eine restriktive Politik Korruption, und wird ihrerseits von letzterer geprägt. Schmiergelder können bei der Ausstellung notwendiger Dokumente verlangt

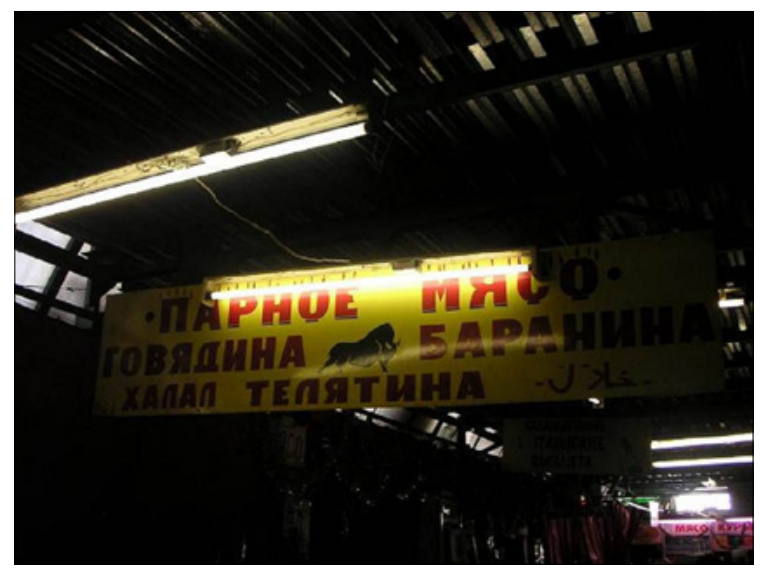

Werbetafel für Halal-Fleisch in einem Moskauer Markt Foto: Matthew Light

werden, oder im Gegenteil dafür, dass die Immigrationsvorschriften nicht angewandt oder Kontrollen der Arbeitskräfte nicht durchgeführt werden. Im gleichen Zusammenhang ist der Unwillen vieler Vermieter zu sehen, Mietern eine Registrierung zu geben, weil sie Scherereien und Erpressung durch die Behörden fürchten. Es gibt zwar Hinweise, dass diese Praktiken im 21. Jahrhundert weniger extrem vorhanden sind, verschwunden sind sie jedoch nicht.

\section{Phasen der postsowjetischen Migrationspolitik}

Die Forschung unterteilt die russische Immigrationspolitik in verschiedene Phasen. Die 1990er Jahre zeitigten eine Politik im Staatsangehörigkeitsrecht, die nach allen internationalen Standards höchst großzügig war und im Wesentlichen auf eine freie Immigration postsowjetischer Staatsangehöriger nach Russland hinauslief. Daneben erfolgte die praktisch unkontrollierte Einreise von Bürgern postsowjetischer Staaten, die Arbeit suchten, was zum Teil auf die rechtlichen Unklarheiten hinsichtlich der Arbeitsrechte von nichtrussischen Staatsangehörigen zurückzuführen war. In den frühen 2000 er Jahren allerdings wurde das Staatsangehörigkeits- und Immigrationsrecht revidiert, um die Einwanderung zurückzufahren und die Arbeitsrechte von Ausländern einzuschränken. Durch diese neue Politik wurde die Erlangung der Staatsbürgerschaft zu einem komplexen, mehrstufigen Prozess, bei dem zeitweilige und ständige Aufenthaltsgenehmigungen Voraussetzung für eine Beantragung der Staatsangehörigkeit waren. Durch die Gesetze wurde es darüber hinaus wahrscheinlicher, dass der vorübergehende Aufenthalt und die Beschäftigung von Gastarbeitern Gesetze verletzt werden. Die Bürger der meisten postsowjetischen Staaten konnten zwar weiterhin visafrei nach Russland einreisen - im Gegensatz, 


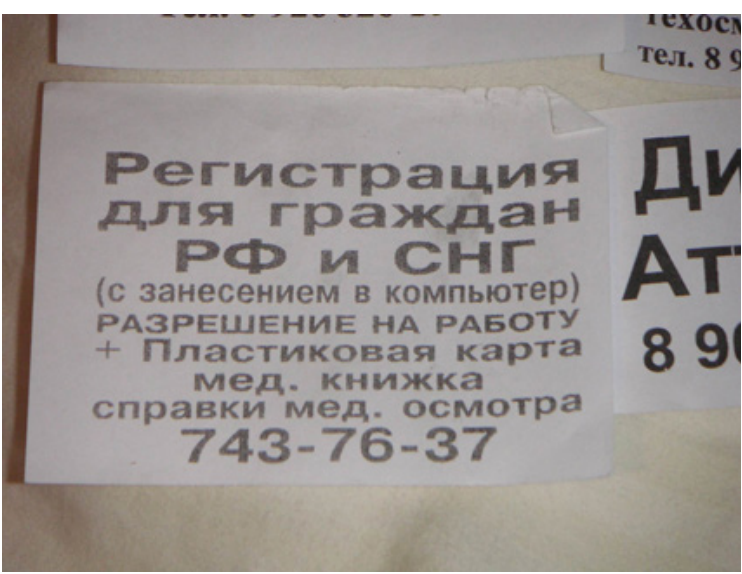

Anzeige für den Service, Zugezogenen bei ihrer Registrierung zu helfen. Diese Dienstleistungen beinhalten häufig Korruption.

Foto: Matthew Light

ist hier anzumerken, zu Menschen aus Lateinamerika die in die USA wollen, oder zu Personen aus Nordafrika und dem Nahen Osten, die in die EU wollen -, doch gab es de jure oder de facto eine Reihe von Maßnahmen, durch die die Betroffenen tendenziell in die Illegalität getrieben werden, wenn sie auf Arbeitssuche eingetroffen sind. Eine dieser Politiken betraf die Schwierigkeit, eine Registrierung des Aufenthalts zu erlangen, eine Vorschrift, die sowohl für Ausländer galt, als auch für Bürger Russlands. Ein weiterer Aspekt bestand in dem Beharren darauf, dass von einem konkreten Arbeitgeber eine Einladung zu erlangen ist, wobei dem Arbeitsmigranten hierfür eine nur sehr begrenzte Zeit eingeräumt wird. Wiederum dürften viele Arbeitgeber nicht bereit sein, formale Arbeitsverträge abzuschließen, entweder, weil so eine Ausbeutung der Arbeiter erleichtert wird, oder aus Furcht vor Erpressung oder Druck seitens der Behörden.

Seit Mitte der 2000er Jahre hat sich die Migrationspolitik Russlands erneut gewandelt, mit weiterer Liberalisierung, stärkerer Restriktivität, fortgesetzten Verschiebungen bzw. einer Ungewissheit, die in unterschiedlichen Bereichen zu Tage trat. Einerseits beschloss die Zentralregierung Maßnahmen zur Legalisierung wenigstens einiger Arbeitsmigranten. $Z u$ diesen Maßnahmen gehörten eine Erleichterung der »vorübergehenden Registrierung « für Gastarbeiter am Arbeitsort wie auch am Wohnort. Darüber hinaus wurde ein neues und international herausragendes System von »Patenten" geschaffen, über die Migranten praktisch periodisch Steuern für das Recht auf vorübergehende Beschäftigung in Russland zahlen. Eine solche Politik verweist auf ein implizites offizielles Eingeständnis, dass massenhafte Illegalität im Zusammenhang mit Einwanderung und Arbeitsmigranten zu verstärkter Unordnung und Korruption führt und die Bürger verärgert. Bemerkens- wert ist auch, dass diese Veränderungen von professionellen Demographen und anderen Sozialwissenschaftlern vorgeschlagen wurden, und dass sich die russische Regierung als empfänglich für solche Ratschläge erwiesen hat. Andererseits sind einige Aspekte der Immigrationspolitik nicht liberalisiert worden, und es hat bei den begrenzten, gerade beschriebenen Veränderungen wieder einige Rückschritte gegeben. Die Registrierung des ständigen Aufenthalts und der Staatsangehörigkeit ist immer noch ein extrem komplizierter Prozess, was darauf hinweist, dass die russische Regierung sich immer noch nicht an die Aussicht auf eine dauerhafte Immigration gewöhnt hat, insbesondere jener durch Nichtslawen. Die Regierung hat auch ein kompliziertes und regional festzulegendes System von Beschäftigungsquoten eingeführt, die zum Teil den liberalisierenden Effekt zunichtegemacht haben, der sich aus dem Übergang von den früher zwingend erforderlichen Beschäftigungsangeboten $\mathrm{zu}$ Immigrationspatenten ergeben hatte.

\section{Nationalismus und Informalität als Ursachen einer widersprüchlichen Politik}

Die Erklärung für diese widersprüchliche Politik umfasst eine Reihe von Faktoren. Zum einen hat Informalität, wie beschrieben, einen kriminellen Wert für Offizielle aller Ebenen, um rechtswidrige Renten mit Hilfe von Korruption abzuzweigen, aber auch, um leichter Kontrolle über eine Person zu erlangen: Russland ist somit ein negatives Beispiel, das die Bedeutung durchsetzbarer Niederlassungs- und Migrationsrechte für die allgemeine Rechtstaatlichkeit illustriert. Caress Schenk hat auf die regionalen Beschäftigungsquoten verwiesen, mit denen aus politischen wie wirtschaftlichen Gründen - ein gewisses Maß an Illegalität bei Gastarbeitern erreicht werden soll, wobei die politischen Gründe wiederum den allgegenwärtigen Unwillen auf allen Ebenen des Staates reflektieren, die Realität eines stärker multikulturellen und insbesondere verstärkt islamischen Russland zu akzeptieren. $\mathrm{Zu}$ beachten ist aber, dass dies nicht als pauschale Kritik an der Gesellschaft in Russland gemeint ist. Russland ist in der Tat immer eine multikulturelle Gesellschaft gewesen; und es ist in mancher Hinsicht systematischer multikulturell als andere Industriestaaten, beispielsweise in Politikbereichen wie dem offiziellen Schutz bestimmter Minderheitensprachen. Gleichwohl haben die Zentralregierung wie auch die Regierungen in vielen Regionen, so stellen es viele Wissenschaftler heraus, einen offiziellen russischen Nationalismus kultiviert, nämlich ein Verständnis der russischen Identität, das den Vorrang der russischen Kultur und der orthodoxen Kirche betont, und die ethnisch oder kulturell andersgearteten Bürgern kühl oder gar feindselig gegenübersteht (ein eigentümliches Beispiel für diesen offiziellen Nationalismus ist die Politik, 
mit der die Immigration der sogenannten "Landsleute» (sootetschestwenniki) gefördert werden soll; die "Landsleute sind eine mehrdeutige Kategorie, die angeblich postsowjetische Staatsangehörige mit einer Affinität zur russischen Kultur umfasst, vielleicht aber in Wirklichkeit ethnische Russen meint). Eine umfassende Reform der Politiken zur Binnenmigration und zur Immigration würde von dem Staat auf allen Ebenen verlangen, sich zu einem offiziellen Multikulturalismus und zu Toleranz zu bekennen. Es würde darüber hinaus den Verzicht auf die allgegenwärtige Informalität bedeuten, die viele Aspekte des gesellschaftlichen Lebens in Russland umfasst.

Beobachter wie Alena Ledeneva haben darauf verwiesen, dass diese Informalität - zum Teil manifestiert in Netzwerken offiziell tolerierter Korruption - in der Tat für das Überleben des Regimes von essentieller Bedeutung ist, da es Funktionäre auf regionaler und föderaler Ebene sowie Manager zementartig an den Kreml bindet. So lang das derzeitige Regime besteht, werden diese beiden Faktoren - der offizielle Einsatz von russischem Nationalismus und die allgegenwärtige Informalität -wohl weiterhin der Liberalisierung der Politik in den Bereichen Immigration und der Binnenmigration Grenzen setzen.

Die Ambivalenz und Fragilität der postsowjetischen Liberalisierung wird auf unterschiedliche Weise auch durch andere Entwicklungen in der russischen Politik illustriert. Seit 2008, als die wirtschaftliche Lage und die Beziehungen zum Westen sich stark eingetrübt haben, hat die Zentralregierung offensichtlich Überlegungen angestellt, ob die totale Ausreisefreiheit eine kluge Sache ist. So hat der Staat Angehörige der Polizei und des Militärs dazu verpflichtet, sich alle Auslandsreisen genehmigen zu lassen, selbst die zu touristischen Zwecken. 20152016, im Gefolge des Streits mit dem Erdoğan-Regime in Bezug auf die Syrien-Krise, erließ die Regierung ein de facto-Verbot für russischen Tourismus in die Türkei, die für Bürger Russlands ein wichtiges Ferienziel gewesen war. Dieser Eingriff in die persönlichen Reisemöglichkeiten ist in der postsowjetischen Zeit beispiellos. Im Zuge einer noch bedrohlicheren Entwicklung hat die Regierung eine neue Vorschrift erlassen, der zufolge alle Bürger Russlands, die auch über eine ausländische Staatsangehörigkeit verfügen oder ihren ständigen Wohnsitz im Ausland haben, dies den russischen Behörden melden müssen und eine Unterlassung strafrechtliche Folgen nach sich zieht. Wenn auch keiner dieser Schritte eine totale Abkehr von der postsowjetischen Ausreisefreiheit bedeutet, so weisen sie doch auf eine Bereitschaft hin diese, herunterzufahren; sie könnten ein offizielles Ausloten sein, wie viel Repression politisch möglich ist.

Ein weiterer Schritt in Richtung eines politischen Migrationsmanagements ist in der Verknüpfung von erleichterten Einwanderungsbedingungen und einer Mitgliedschaft in der Eurasischen Wirtschaftsunion (EAWU) zu sehen. Diese Organisation soll postsowjetische Staaten mit Russland integrieren und vermutlich deren Integration mit der Europäischen Union (oder gar eine Mitgliedschaft) ausschließen, also eine Entwicklung, die aus russischer Sicht nicht hinnehmbar ist. Bürger postsowjetischer Staaten wie Kirgistan, die der EAWU beigetreten sind, werden nun bevorzugten Zugang zum russischen Arbeitsmarkt haben, anders als Bürger von Nicht-Mitgliedsstaaten. Fairerweise ist zu sagen, dass dieses Instrument einer Konditionierung internationaler Migrationsrechte durch politische und internationale Integration auch in anderen Teilen der Welt kaum unbekannt sein dürfte: Tatsächlich stellen sie eine Parallele zu einer ähnlichen Politik der Europäischen Union dar. Fragwürdiger ist vielmehr der Einsatz von Methoden der Nötigung, um Staaten zum Beitritt zur EAWU zu bewegen, was weithin als ein Instrument russischer Kontrolle über die postsowjetische Region betrachtet wird. Interessant ist hier die Frage, in welchem Maße eine solche Nötigung durch einen autoritären Staat möglicherweise einer tatsächlich liberalen Migrationspolitik zum Aufstieg verhelfen könnte, die auf Achtung der Menschenrechte und Rechtstaatlichkeit beruht.

Diese Überlegung führt zu der grundlegenden Frage, was die postsowjetische Migrationspolitik Russlands im internationalen Vergleich heraushebt, oder eben auch nicht. Generell lässt sich sagen, dass die derzeitige Politik Russlands systemisch weniger Unterschiede zu den entsprechenden Politiken im Westen aufweist, als noch zu Sowjetzeiten: Der Staat hat zumindest formal bestimmte Arten der Kontrolle über die eigenen Bürger abgeschafft und er erkennt, dass in großer Zahl eine Einreise ausländischer Staatsbürger stattfinden wird. Darüber hinaus wäre es zu einfach zu sagen, dass die Politik Russlands (in jeder Hinsicht) »repressiver« sei, auch wenn hier weiterhin beträchtliche Unterschiede zwischen der russischen Politik und (zusammengefasst) der im Westen bestehen. Zutreffender wäre es, die Migrationsrechte hinsichtlich der Mobilität nach, innerhalb und nun wohl aus Russland als fragiler und schwächer als in den industrialisierten Demokratien zu bezeichnen. Informalität und fehlende Ordnung im Gegensatz zu schierer Repression sind heute die Markenzeichen der Migrationspolitik in Russland.

Übersetzung aus dem Englischen: Hartmut Schröder

Informationen über den Autor und Lesetipps finden Sie auf der nächsten Seite. 
Über den Autor

Matthew Light erlangte seinen Doktortitel in Politikwissenschaft 2006 an der Yale-Universität. Seit 2008 ist er an der Universität Toronto tätig, wo er gegenwärtig Associate Professor für Criminology and Sociolegal Studies ist. Zu seinen Forschungsschwerpunkten gehören Migrationspolitik, Polizeiwesen und die Strafjustiz in der postsowjetischen Region.

\section{Lesetipps}

- Light M.: Fragile Migration Rights: Freedom of Movement in Post-Soviet Russia, Abingdon, Oxon, New York, NY: Routledge 2016.

- Schenk C.: Controlling Immigration Manually: Lessons from Moscow (Russia), in: Europe-Asia Studies, 65. 2016, Nr. 7, S. 1444-65.

\section{Grafik 1: Internationale Migration von und nach Russland 1997-2015 (Personen)}

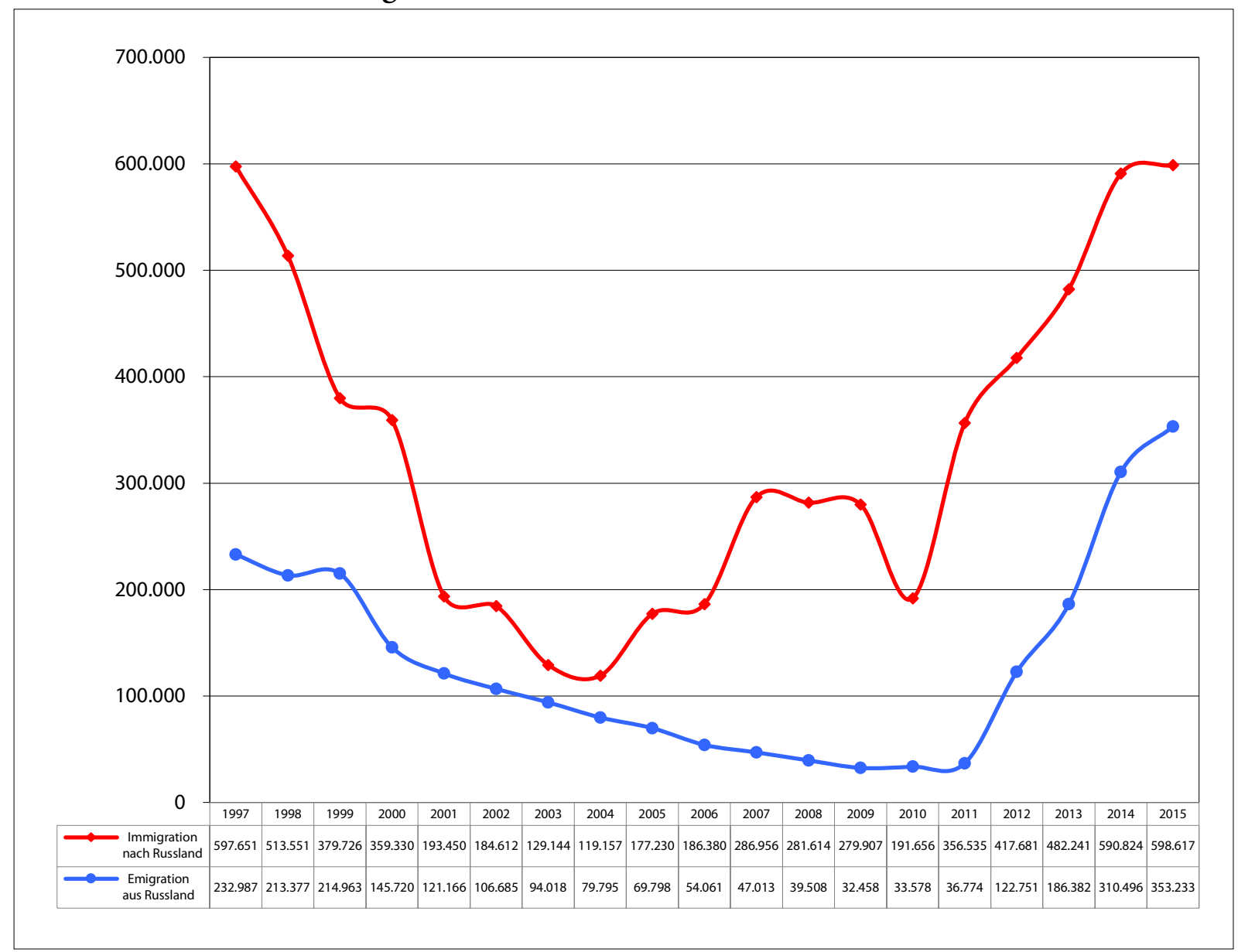

Quelle: Angaben von Rosstat <http://www.gks.ru/free_doc/new_site/population/demo/migr2.xls, 1. März 2017> 
Grafik 2: Zuwanderung nach Russland 2015 (Zehn wichtigste Zuwanderländer und „Andere«)

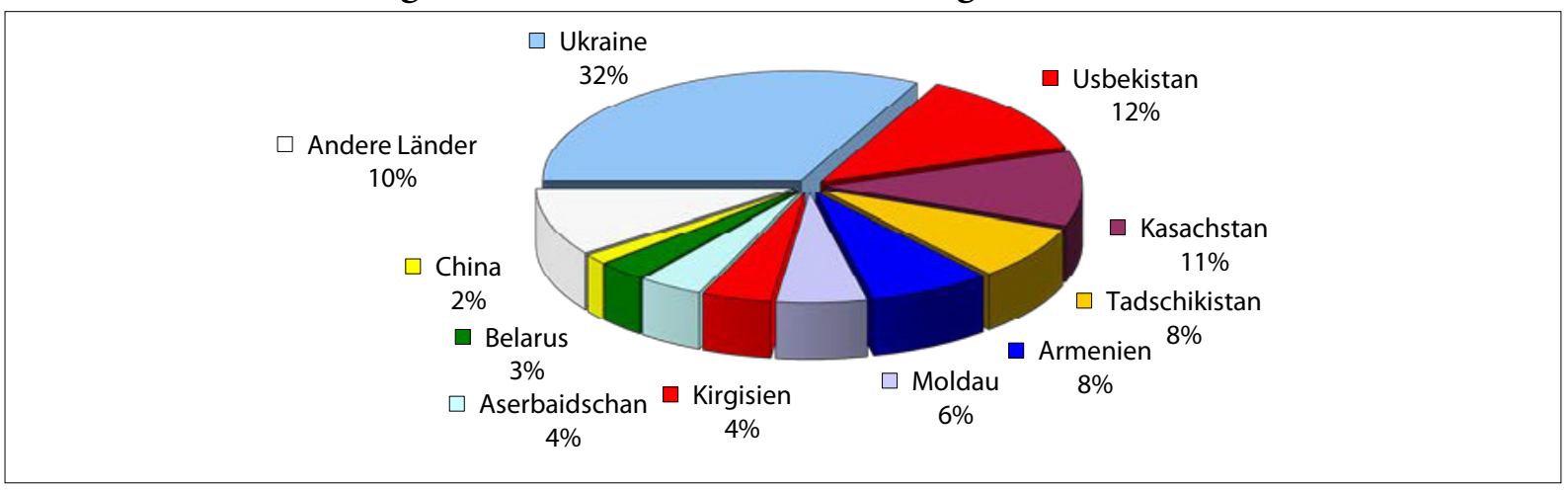

Quelle: Angaben von Rosstat <http://www.gks.ru/free_doc/new_site/population/demo/migr2.xls, 1. März 2017>

\section{Grafik 3: Migrationsbewegungen in Russland (Schätzung Frühjahr 2008)}

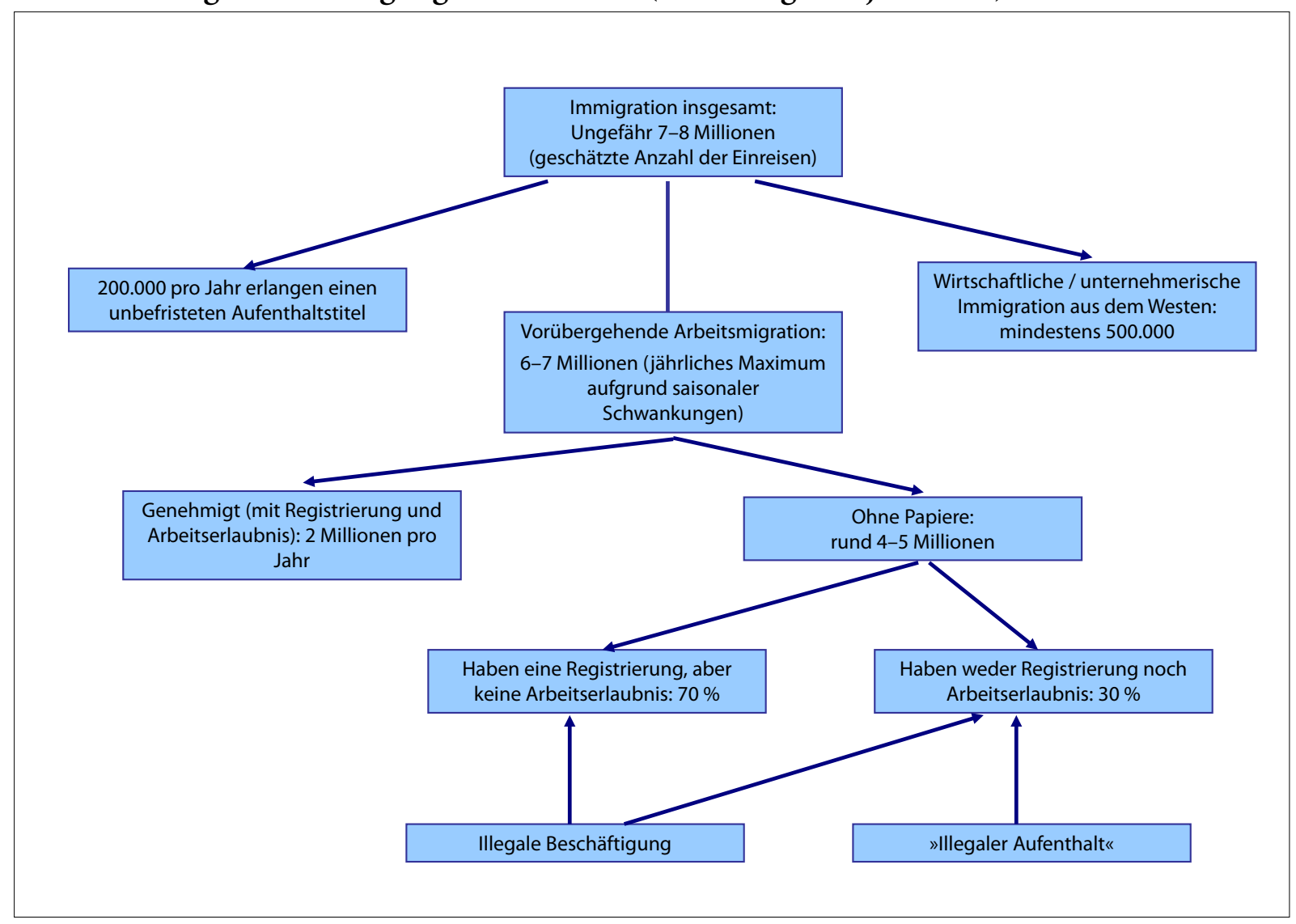

Quelle: Matthew Light 


\section{One way ticket oder vorübergehende Zuflucht? Flüchtlinge aus der Ukraine in Russland}

Irina Kuznetsova, Birmingham

\section{Zusammenfassung}

Russland hat Hunderttausenden Bürgern der Ukraine aus den Gebieten des bewaffneten Konflikts zeitweilige Zuflucht gewährt, die von dort fliehen mussten. Russland gewährt ihnen zwar keinen Flüchtlingsstatus, doch genießt diese Kategorie Migranten besondere Rechte. Der Diskurs zur Hilfe für die Flüchtlinge aus der Ukraine bewegt sich zwischen der offiziellen Rhetorik vom »Brudervolk«, Mitgefühl von Seiten eines Teils der Gesellschaft sowie negativen Haltungen bei Migrationsgegnern. Die Spaltung in der ukrainischen Gesellschaft und die Angst vor einer Rückkehr in die Heimat haben eine sehr große Zahl der Migranten dazu genötigt, in Russland zu bleiben, was im Kontext einer zukünftigen Politik zur Aussöhnung und Stabilisierung der Lage im Südosten der Ukraine zusätzliche Fragen aufwirft.

\section{Einführung}

Die jüngste Nachricht, dass Russland die von den Strukturen der Separatisten in der Ostukraine ausgestellten Pässe anerkennt, hat weltweit in den Medien Beachtung gefunden. Die Anerkennung von Ausweisen der Volksrepubliken Donezk und Luhansk sind der »Washington Post" vom 18. Februar 2017 zufolge »ein umstrittener Schritt, der Moskau einer de facto-Anerkennung der abtrünnigen Republiken näher bringt«. In Russland wird das als eine "technische Frage« betrachtet, die in Russland der Angleichung der Rechte von Migranten aus diesem Teil der Ukraine dienen soll. »Etwas irgendwie Politisches kann ich hier nicht erkennen, von einer Anerkennung kann hier keine Rede sein«, kommentierte der Vorsitzende des Auswärtigen Ausschusses des Föderationsrates, Wladimir Dshabarow, den Erlass des Präsidenten (TASS, 18. 02. 2017).

Der Erlass war zweifellos nicht "technischer", sondern politischer Natur. Allerdings lohnt sich ein Blick aus einer anderen Richtung auf die politische Komponente des Erlasses, indem wir nämlich die Frage betrachten, wie es um die Lage der Flüchtlinge aus der Ukraine in Russland bestellt ist, und was für eine Zukunft vor ihnen liegen könnte.

\section{Die soziale und rechtliche Situation der Flüchtlinge aus der Ukraine in Russland} Der bewaffnete Konflikt zwischen der international nicht anerkannten »Volksrepublik Donezk« (DNR) und der »Volksrepublik Luhansk“ (LNR) einerseits sowie der Zentralregierung der Ukraine andererseits hat den südöstlichen Teil der Ukraine an den Rand einer humanitären Katastrophe gebracht. Seit dem April 2014 sind über 9.700 Menschen umgekommen und eine Vielzahl von Schulen und Infrastrukturobjekten zerstört worden (UN OCHA: Humanitarian needs overview Ukraine, 2017; <https://www.humanitarianresponse.info/system/ files/documents/files/ukraine_humanitarian_needs overview_2017_eng.pdf>). Über 1,3 Millionen Menschen sind zu Flüchtlingen geworden, von denen ein großer Teil in Russland (1,09 Millionen) und Belarus (130.000) Zuflucht suchte (nach Angaben des UNHCR von 2016). Rund 1,7 Millionen Menschen mussten in andere Teile der Ukraine fliehen. Dem »Internal Displacement Monitoring Centre« zufolge weist die Ukraine heute die weltweit achtgrößte Gruppe von Binnenflüchtlingen (internally displaced persons, IDP) auf.

Von Beginn des bewaffneten Konfliktes an trafen Tausende Flüchtlinge in Russland ein, organisiert - in das Gebiet Rostow, wo sie in Übergangslagern untergebracht wurden -, wie auch eigenständig. Aus dem Gebiet Rostow wurden die Flüchtlinge nach einem Quotensystem in verschieden Regionen Russlands gebracht. Moskau und St. Petersburg waren sehr bald für eine Registrierung als zeitweiliger Flüchtling versperrt. Unter den Personen, die als vorläufige Flüchtlinge anerkannt wurden, sind zu ungefähr gleich großen Teilen Männer und Frauen sowie zu 70 Prozent Personen im erwerbsfähigen Alter und 23 Prozent Kinder unter 15 Jahren (Stand vom 01. 01. 2016, laut der Statistikbehörde »Rosstat«)

Einer Erklärung der Leiterin der Hauptverwaltung für Migrationsfragen des russischen Innenministeriums, Olga Kirillowa, zufolge halten sich derzeit rund 2,5 Millionen Bürger der Ukraine in Russland auf, von denen rund eine Million aus dem Südosten der Ukraine stammen. Von diesen wiederum haben 442.000 um "zeitweilige Zuflucht" (wremennoje ubeshischtsche) nachgesucht; 411.000 haben eine vorübergehende Niederlassungserlaubnis beantragt, über 230.000 wollten in das "Staatlichen Programm zur Förderung der freiwilligen Umsiedlung von im Ausland lebenden Landsleuten in die Russische Föderation" aufgenommen werden und 175.000 haben ihre Unterlagen zum Erhalt der russischen Staatsangehörigkeit eingereicht (4. Januar 2017, 
Pressekonferenz des Innenministeriums). Unter den Personen, die im Jahr 2015 die russische Staatsangehörigkeit erlangten, waren zu einem Drittel ehemalige Bürger der Ukraine.

Auch wenn Russland diese große Anzahl Flüchtlinge aufgenommen hat, wird deren Status meist entweder als "Personen, die zeitweilige Zuflucht erhalten haben« eingestuft, oder aber in seltenen Fällen als »Vertriebene" (wynushdjonnyje pereselenzy). Den Status eines "Flüchtlings« (beshenez) haben zwischen 2014 und 2016 lediglich 688 Personen aus der Ukraine erhalten (Angaben von »Rosstat»).

Wie viele Flüchtlinge aus der Ukraine gibt es in Russland tatsächlich? Diese Frage ist mit Hilfe der offiziellen Statistiken nicht zu beantworten. Nach dem Zerfall der UdSSR ist Russland aufgrund der Visafreiheit, der stark entwickelten sozialen Bindungen und fehlender Sprachbarrieren eines der häufigsten Ziele für Arbeitsmigranten aus der Ukraine gewesen. Daher ist die Entscheidung für Russland als Zufluchtsland auch dadurch diktiert worden, dass die Menschen beim Beginn der Kampfhandlungen entweder sich bereits zur Arbeit in Russland befanden oder aber wussten, wohin sie fahren können.

Da die Dokumente für eine "zeitweilige Zuflucht" ständig verlängert werden müssen, schreckten viele Flüchtlinge vor dieser Ungewissheit zurück und wollten nicht nach Hause zurückkehren, selbst wenn ihre Stadt wieder unter die Kategorie "ungefährlich« fällt. Unsere Studie hat ergeben, dass viele dieser Personen lieber um eine Arbeitserlaubnis nachsuchen oder aber inoffiziell zu arbeiten begannen und für längere Zeit im Lande blieben.

Seit Beginn des Konflikts hat die Ukraine die Ausstellung von Dokumenten für Bewohner der »Volksrepubliken" in der Ostukraine eingestellt. Die meisten dieser Bewohner trafen in Russland mit Dokumenten der DNR oder der LNR ein. Dieser Umstand hat die Feststellung ihres rechtlichen Status komplizierter gemacht, weil sie dadurch unter die Kategorie der Migranten ohne Papiere fallen, was nicht selten zu einer Abschiebung führt. In anderen Fällen hatten die Flüchtlinge zwar einen ukrainischen Pass, aber Bildungsnachweise, die von den Stellen der Aufständischen ausgestellt waren. Dann hatten sie Probleme eingestellt zu werden oder sich an einer Hochschule oder einem College zu immatrikulieren.

Im Mai 2016 wurde ein Gesetz verabschiedet, das für Flüchtlinge und Personen, die in Russland zeitweilige Zuflucht erhalten hatten, den Erhalt einer Niederlassungserlaubnis erleichtert (Föderales Gesetz Nr. 129-FZ vom 1. Mai 2016). Nun können diese Personenkategorien, wie auch Teilnehmer am »Staatlichen Programm zur Förderung der freiwilligen Umsiedlung von im Aus- land lebenden Landsleuten in die Russische Föderation«, eine Niederlassungserlaubnis erhalten, ohne vorher eine Aufenthaltserlaubnis ausgestellt bekommen zu haben. Die Niederlassungserlaubnis bedeutet unter anderem ein Recht auf Altersversorgung, das Recht, den Wohnort zu wechseln, Wahlrechte, das Recht auf Einstellung ohne Vorlegen einer Arbeitserlaubnis und das Recht auf Hypothekendarlehen.

Als weitere Bevorzugung von Flüchtlingen aus den Konfliktgebieten in der Ukraine hinsichtlich ihres rechtlichen Status ist zu nennen, dass ihnen der Status "zeitweilige Zuflucht» für ein ganzes Jahr gewährt wird, während ukrainische Staatsangehörige aus anderen Regionen der Ukraine sich seit November 2015 nur 90 Tage innerhalb eines halben Jahres ohne entsprechende Genehmigung in Russland aufhalten dürfen. Bei der Ausstellung der Ausweise für Personen, die zeitweilige Zuflucht erhielten, wird der ukrainische Pass einbehalten. Das führt dazu, dass viele Flüchtlinge nicht nach Hause fahren können, um noch Unterlagen zu holen, Verwandte zu besuchen oder nachzuschauen, ob ihr zurückgelassenes $\mathrm{Hab}$ und Gut unversehrt ist.

Unsere Studie hat ergeben, dass Flüchtlinge aus der Ukraine trotz dieser günstigen Vorschriften oft den gleichen Problemen begegnen, wie die anderen Migranten: Bürokratie, Unklarheit und Ambivalenz des Quotensystems und der Arbeitsbeschaffung.

\section{Warum Russland?}

Unserer Studie hat festgestellt, dass bei der Entscheidung für Russland als Zufluchtsland folgende Gründe eine Rolle spielten: 1) jemand hat Verwandte oder Freunde in Russland; 2) Notevakuation mit Hilfe russischer humanitärer Stellen aus dem Gebiet der Kampfhandlungen; 3) wirtschaftliche Motive (Hoffnung, eine Arbeit zu finden); 4) Sorge um die persönliche Sicherheit (Furcht vor Gerichtsverfahren in der Ukraine; Furcht vor Diskriminierung); 5) russische Staatsangehörigkeit bei einem der Familienmitglieder.

Die Haltung gegenüber Leuten aus den Aufstandsgebieten in der Ukraine ist oft ambivalent. Studien, die in der Ukraine durchgeführt wurden, haben in der Bevölkerung ein Misstrauen festgestellt, dass Leute aus dem Donbass die Separatisten unterstützen könnten. Von Spaltungen sind auch Familien betroffen. So verweigerten ukrainische Verwandte einer der Interviewten ihre Hilfe: "Was denn, hat man dort noch nicht alle von euch umgebracht? Haben euch die Separatisten noch nicht beschossen?« (Frau, 24 J.). Die Frau fuhr letztendlich zu entfernten Verwandten nach Kasan (Tatarstan). Eine ähnliche Geschichte hat ein anderer Gesprächspartner erlebt: »Hier [in Russland] haben wir Verwandte in Tatarstan. Sie haben darauf bestanden, dass wir kom- 
men, weil sie sehr große Angst um unser Leben hatten, ganz anders, als jene Verwandten, die in der Ukraine lebten. Die standen wohl unter dem Eindruck der Informationen und der Medien; und die Separatisten, Terroristen und das alles... Das hat verhindert, dass sie unsere tatsächliche Lage richtig wahrnehmen« (Mann, 48 J.).

Eine der Interviewten, eine Angehörige der Separatistenmilizen, bekennt: »Als ich wegmusste, war es für mich keine Frage, ob ich in die Ukraine gehe oder nach Russland - ganz klar nach Russland. Ich kam nicht einmal auf den Gedanken, auf die ukrainische Seite zu gehen [...] Ich bin mit meinen Kindern und den nächsten Verwandten gekommen, weil, wenn man daran denkt, dass in der Ukraine nach mir gefahndet wird, dann hätten die vielleicht Verhöre über sich ergehen lassen müssen, und das ist sehr unangenehm « (Frau, 25 J.). Interessant ist, dass diese Frau in der Region, in der sie längere Zeit bei Bekannten lebt, keine zeitweilige Zuflucht erhielt und informell arbeitet, da sie für eine offizielle Arbeitserlaubnis nicht genügend Geld hat.

Neben den Verwandten als Motiv waren wirtschaftliche Gründe am häufigsten: »Ich habe natürlich vorgeschlagen, nach Dnipropetrowsk [in der Ukraine] zu gehen, weil er da immerhin Verwandte hat und es doch dichter an Donezk liegt; in Donezk sind auch noch Verwandte geblieben [...]. Aber wir haben dann doch gedacht, dass sich die Lage nicht bessern wird. Und wir haben geschaut, wie viele Schulden die Ukraine hat, [...] die Ukraine selbst begann zu zerfallen, und wird das auch weiterhin« (Frau, 25 J.

Die Interviews mit den Flüchtlingen haben gezeigt, dass sie in ihrer Mehrheit beabsichtigen, in Russland zu bleiben. Einer neueren Umfrage zufolge, die vom Berliner Zentrum für Osteuropa- und internationale Studien (ZOiS) durchgeführt wurde, haben 80 Prozent der befragten Flüchtlinge aus der Ukraine nicht vor, zurückzukehren.

\section{"Brudervolk"}

Der Hohe Flüchtlingskommissar der Vereinten Nationen, Filippo Grandi, hat jüngst erklärt, dass er bei der Aufnahme vom Flüchtlingen, unter anderem aus Syrien, sehr auf die Hilfe Russlands hofft: „Wir schätzen die Arbeit äußerst, die Russland in Bezug auf Hunderttausende ukrainischer Flüchtlinge geleistet hat. Es wäre zu wünschen, dass auch die Bitten Zufluchtsuchender anderer Nationalität, etwa von Syrern [...] auf positive Weise bearbeitet würden« (TASS, 22. Februar 2017). Die Flüchtlingspolitik erscheint höchst selektiv: So haben etwa mit Stand vom 1. Januar dieses Jahres zwei Syrer den Status eines "Flüchtlings« erhalten; 1317 weitere erhielten »zeitweilige Zuflucht». Die Zahl der Personen aus anderen Krisengebieten, die in Russ- land Zuflucht fanden, ist noch geringer (Angaben von Rosstat).

Diese Selektivität entspringt geopolitischen Interessen, und darüber hinaus Vorstellungen von einer gemeinsamen Kultur und Sprache. Brudervolk - diese Wortbildung spielte in der offiziellen Rhetorik zur Hilfe für Flüchtlinge aus der Ukraine eine Schlüsselrolle. So sagte Sergej Iwanow im Jahr 2014 als Leiter der Präsidialadministration: „Was dort geschieht - ich möchte hier keine großen Worte bemühen - ist ein Bürgerkrieg, der sich zielstrebig zu einem Genozid am eigenen Volk entwickelt. Es ist klar, dass wir es mit einer humanitären Katastrophe zu tun haben. Wir aber, die regionalen und föderalen Behörden, werden natürlich reagieren und auf jede erdenkliche Art helfen. Ich wiederhole: Das sind völlig unschuldige Menschen, das ist ein Brudervolk“ (Fernsehsender "Perwyj kanal, 19. Juni 2014). Auch Wladimir Putin sprach mehrfach vom "Brudervolk«.

An der Flüchtlingshilfe beteiligte sich auch die Russische Orthodoxe Kirche. Die Synodalabteilung für Wohlfahrtsfragen hat insgesamt 131 Millionen Rubel Hilfsgelder für Flüchtlinge aus der Ukraine gesammelt (Agentur für religiöse Information "Blagowest info", 12. Januar 2016).

Es ist höchst interessant, dass während von offiziellen Stellen und der Kirche eine Rhetorik vom »Brudervolk« zu hören war, die Flüchtlingshilfe von Seiten einer Reihe von Wohlfahrtsorganisationen im Ton eines "Wir helfen Neurussland" präsentiert wurde. So wird das Kuratorium einer der größten privaten wohltätigen Stiftungen, die Flüchtlingen aus der Ukraine hilft - der Stiftung des Heiligen Wladimir des Großen - von dem Geschäftsmann Konstantin Malofejew geleitet, gegen den Sanktionen der Europäischen Union und Kanadas bestehen, und gegen den in der Ukraine ein Strafverfahren wegen Unterstützung für Terroristen eröffnet wurde (s. die Recherche von »RBC.ru«, 08. 09. 2014).

Durch die Ankunft einer riesigen Anzahl von Flüchtlingen gab es in Russland 2014 eine Welle der humanitären Hilfe und Freiwilligenarbeit. Die lokalen Behörden und die Zivilgesellschaft handelten gemeinsam und schafften es, rechtzeitig materielle und medizinische Hilfe bereitzustellen, die Kinder der Flüchtlinge in Schulen unterzubringen und in Sanatorien und Ferienlagern eine bequeme Unterkunft einzurichten. Der Staat zahlte diesen Einrichtungen 800 Rubel pro Tag und Person für Unterkunft und Verpflegung. Es wurde eine unglaubliche Arbeit geleistet; die Menschen wurden nicht der Straße überlassen.

Die Schlussfolgerung, dass allein die offizielle Rhetorik und der politische Wille zu dem Aufschwung des Freiwilligenengagements und des Mitgefühls für die Flüchtlinge geführt haben, wäre nicht zutreffend. Viele 
Befragte berichteten von der Großzügigkeit ihnen unbekannter Menschen, die ihnen mitunter sogar ihre Wohnung zur Verfügung stellten. Und das schlichte Mitgefühl war sehr wichtig: »2014, als wir herkamen, zeigten die Behörden stets, sagen wir mal, wie in jedem Land, eine gewisse Trägheit auf lokaler Ebene. Was aber die Haltung der Menschen angeht, da waren wir einfach von der tiefgreifenden Güte der Leute vor Ort, der Kasaner, sehr bewegt. Wenn die Leute einen kleinen Akzent hörten und fragten: , Sie sind wohl nicht von hier... Woher kommen Sie denn...? Und wenn wir dann sagten: aus der Ukraine, da unterhielten sich einige, und sie hatten Tränen in den Augen wegen der Ereignisse« (Mann, $48 \mathrm{~J}$.).

Im Alltag allerdings erfuhren die Zugezogenen nicht nur einen herzlichen Empfang, sondern auch Fremdenfeindlichkeit: "Irgendwie heißt es, dass alle chochly [pejorativer Spitzname für Personen aus der Ukraine; I.K.], nun ich habe es mehr als einmal erlebt, und in den sozialen Netzwerken, und einige äußern sich nicht sehr nett über Ukrainer. $\mathrm{Na}$, dass [wir] Ukrainer von der Versorgung des Staates leben, dass wir Stütze kriegen, nur rumsitzen und nichts tun (Frau, 25 J.). Der typische Diskurs der Empfängergesellschaft über Migranten, die angeblich auf Staatskosten leben und der einheimischen Bevölkerung die Arbeitsplätze wegnehmen, hat in vielen Fällen auch Menschen aus der Ukraine getroffen.

\section{Bleiben oder zurückkehren?}

Eine Nachricht ist kürzlich von den Medien praktisch unbeachtet geblieben: Am 1. Februar 2017 haben die Auffanglager und -wohnheime für Personen aus der Ukraine, die in Russland Zuflucht suchen, ihre Arbeit eingestellt. Das geschah trotz Awdijiwka und der anhaltenden Kämpfe. Das Problem der Flüchtlinge aus der Ukraine verschwand bereits 2015 ganz allmählich aus den Schlagzeilen der landesweiten Medien. Die nichtkommerziellen Organisationen räumen ein, dass es jetzt schwieriger geworden ist, humanitäre Hilfe zu mobilisieren. Die Anerkennung der Ausweise der DNR und der LNR sowie das erleichterte Verfahren für Menschen aus der südöstlichen Ukraine zur Erlangung der russischen Staatsangehörigkeit oder einer Aufenthaltsgenehmigung erleichtern nicht automatisch das Problem der sozialen Eingliederung oder schlichtweg des Überlebens. Der Bürokratiedschungel bei der Erlangung eines rechtlichen Status, das Fehlen eines "Airbags « in Form von Sozialleistungen oder die Bedingungen der provisorischen Unterkunft bringen Hunderttausende in eine qualvolle Lage.

Darüber hinaus ist anzunehmen, dass es hier um eine Fahrt ohne Rückfahrkarte geht; die Menschen haben einfach Angst zurückzukehren, selbst wenn sich die Lage stabilisiert. Die Spaltung in der ukrainischen Gesellschaft hat praktisch dazu geführt, dass die Flüchtlinge hinsichtlich ihrer Staatsangehörigkeit und Zugehörigkeit widersprüchliche Gefühle hegen. Wenn sie sich für ein Leben in Russland entscheiden, wurden sie davon geleitet, dass sie nichts zu verlieren haben. Das ist sehr beunruhigend: Wer wird die Gebiete Donezk und Luhansk wieder aufbauen? Wer wird zur zivilen Stütze eines Friedensprozesses, wie wird die Integration jener geschehen, die dennoch in die Ukraine zurückkehren? Diese Fragen verlangen größte Aufmerksamkeit.

Übersetzung aus dem Russischen: Hartmut Schröder

Dieser Beitrag wurde im Rahmen eines Projektes verfasst, das mit Mitteln der British Academy gefördert wird. Die Studie der Autorin beinhaltete Interviews mit Flüchtlingen aus der Ukraine, Vertretern der Zivilgesellschaft und der Behörden in Kasan und Moskau.

\section{Über die Autorin}

Irina Kuznetsova ist Birmingham Fellow an der School of Geography, Earth and Environmental Sciences der Universität Birmingham. Sie leitet gegenwärtig ein Projekt, das von dem Forschungsprojekt "Ukraine’s hidden tragedy: understanding of the outcomes of population displacement from the war-torn regions" (<www.idpukraine.com $>$ ) gefördert wird. In ihrer Arbeit hat sie sich auf Migration in Russland und Zentralasien sowie auf kritische Urbanistik und Politikstudien in postsozialistischen Ländern spezialisiert.

\section{Lesetipps}

- Brock, G.: The informal economy of Rostov Oblast on the eve of the Ukrainian refugee crisis, in: Journal of Policy Modeling 37, no. 5 (2015), S. 789-803.

- $\quad$ Round, J., and Kuznetsova, I.: Necropolitics and the Migrant as a Political Subject of Disgust: The Precarious Everyday of Russia's Labour Migrants, in: Critical Sociology 42, no. 7-8 (2016), S. 1017-1034.

- Schenk, C.: Assessing Foreign Policy Commitment Through Migration Policy in Russia, in: Demokratizatsiya: The Journal of Post-Soviet Democratization 24, no. 4 (2016), S. 475-499. 


\title{
Wer kommt?
}

\section{Die aktuelle Entwicklung des Zuwanderungsmanagements Russlands}

\author{
Olga Gulina, Berlin / Moskau
}

\section{Zusammenfassung}

Dieser Beitrag beschreibt die demographischen Perspektiven Russlands und die Bedeutung der Migration für die Existenz und die weitere Entwicklung Russlands. Zuwanderung ist die einzige Möglichkeit für das heutige Russland, seine demografische Balance zu bewahren, den sozialen Verpflichtungen des Staates nachzukommen und einen Bevölkerungsschwund im Land zu verhindern. Besondere Berücksichtigung erfährt das Wesen des Migrationsmanagements in Russland, wie auch die Frage, wie Institutionen des Migrationsrechts als Instrumente der Außenpolitik eingesetzt werden.

\section{Das Humankapital Russlands}

Das postsowjetische Russland hatte seinen demographischen Höhepunkt 1993 erreicht, als die Bevölkerungszahl des Landes 148,6 Millionen betrug. Die folgenden zwei Jahrzehnte erfolgte ein erheblicher natürlicher Bevölkerungsrückgang (zwischen -6,6\% im Zeitraum 2000-2001 und -0,03\% im Jahr 2012), der von einem dynamischen Migrationszuwachs begleitet wurde (zwischen 1,7\% im Jahr 2002 und 6,7\% im Jahr 1994; s. Sacharow, S. W. (Hg): Naselenie Rossii 2014, Moskau, 2016, S. 16).

Ab 2009 verzeichnete Russland einen schwachen natürlichen Bevölkerungszuwachs (+0,2 \% im Jahr 2013, < http:// demoscope.ru/weekly/2016/0677/barom01.php>[russ.]); 0 \% im Jahr 2016, Föderale Statistikbehörde »Rosstat«, 2017; s. <http://www.gks.ru/free_doc/2016/demo/edn12-16.htm> [russ.]), der mit der Entwicklung des Migrationszuwachses nicht vergleichbar war. In den Jahren 2014 bis 2015 erfolgte ein erheblicher Bevölkerungszuwachs um 2,3 Millionen aufgrund der Bildung zweier neuer Föderationssubjekte durch die Inkorporation (Annexion) der Republik Krim (+1,9 Mio.) und der Stadt föderaler Bedeutung Sewastopol (+0,4 Mio.). Mit Stand vom 1. Januar 2017 betrug die Bevölkerungszahl Russlands 146.838.993 (gegenüber 146.691.852 im Jahr 2016) (Rosstat: Vorläufige Schätzung zur Bevölkerungszahl Russlands zum 1. Januar 2017 und im Durchschnitt 2016 [russ.]; <http://www.gks.ru/wps/wcm/ connect/rosstat_main/rosstat/ru/statistics/population/demography/>).

Die Demographen haben im vergangenen Jahr in 41 Föderationssubjekten einen natürlichen Bevölkerungszuwachs festgestellt (2015 war das in 43 Regionen der Fall), wie auch eine anhaltende Tendenz eines Rückgangs des menschlichen Potentials in den meisten russischen Regionen. Von der negativen demographischen Entwicklung waren am stärksten die Regionen des Zentralen Föderalbezirks betroffen (-1,8\% im Jahr 2016, -1,7 \% im Jahr 2015), der Föderalbezirk Nordwest (-0,7\% bzw. $-0,9 \%)$, der Föderalbezirk Süd (-1,0\% bzw. 0,8\%) und der Föderalbezirk Wolga $(-0,7 \%$ bzw. $-0,6 \%)$.

Tabelle 1: Demographische Entwicklung in ausgewählten Föderationssubjekten Russlands 2015-2016 (in Prozent)

\begin{tabular}{|l|c|c|}
\hline & $\mathbf{2 0 1 6}$ & $\mathbf{2 0 1 5}$ \\
\hline Gebiet Amur & $-0,8$ & $-0,6$ \\
Jüdisches Autonomes Gebiet & $-1,7$ & $-1,4$ \\
Gebiet Kaliningrad & $-0,1$ & $-0,5$ \\
Leningrader Gebiet & $-4,8$ & $-5,0$ \\
Gebiet Magadan & $-0,2$ & 0,0 \\
Gebiet Murmansk & $-0,3$ & 0,4 \\
Gebiet Nowgorod & $-5,6$ & $-5,7$ \\
Gebiet Orjol & $-5,3$ & $-5,2$ \\
Region Primorje & $-1,4$ & $-0,8$ \\
Gebiet Pskow & $-6,8$ & $-7,1$ \\
Republik Mordwinien & $-4,2$ & $-4,5$ \\
\hline
\end{tabular}


Tabelle 1: Demographische Entwicklung in ausgewählten Föderationssubjekten Russlands 2015-2016 (in Prozent) (Fortsetzung)

\begin{tabular}{|l|c|c|}
\hline & $\mathbf{2 0 1 6}$ & $\mathbf{2 0 1 5}$ \\
\hline Gebiet Rjasan & $-4,5$ & $-4,7$ \\
Gebiet Samara & $-1,3$ & $-1,4$ \\
Gebiet Smolensk & $-5,8$ & $-5,8$ \\
Gebiet Tambow & $-6,2$ & $-6,2$ \\
Gebiet Twer & $-6,4$ & $-6,4$ \\
Gebiet Tula & $-6,8$ & $-6,6$ \\
Gebiet Uljanowsk & $-3,2$ & $-3,0$ \\
\hline
\end{tabular}

Quelle: Rosstat: Demographische Entwicklung in den Föderationssubjekten Russlands vom Januar 2016 bis Dezember 2016 [russ.], 2017 ; <http://www.gks.ru/free_doc/2016/demo/edn12-16.htm>

Gegenwärtig stellt Immigration - vor allem die aus den nun unabhängigen Republiken der ehemaligen UdSSR - das einzige Mittel zur Kompensierung der Bevölkerungsverluste Russlands dar. Die demographischen Perspektiven des Landes hängen unmittelbar von der Entwicklung der Migration ab. Den Berechnungen der Föderalen Statistikbehörde »Rosstat« zufolge bestehen für Russland drei Szenarien der demographischen Entwicklung bis 2050:

- das erste geht von einem natürlichen Bevölkerungsrückgang um 36,9 Millionen aus, der zum Teil durch 7,7 Millionen Immigranten kompensiert werden würde;

- das zweite nimmt einen natürlichen Bevölkerungsrückgang um 16,1 Millionen an, dem 13,6 Millionen Immigranten gegenüberstehen;

- der dritte rechnet mit einem natürlichen Bevölkerungszuwachs Russlands um 3,1 Millionen und einer Zuwanderung von 19 Millionen neuer Immigranten (Rosstat: Demographisches Jahrbuch Russlands, 2015; <http://www. gks.ru/free_doc/doc_2015/demo15.pdf> [russ.]).

Angesichts der derzeitigen wirtschaftlichen und demographischen Entwicklung Russlands erscheint das zweite Szenario als das wahrscheinlichste.

\section{Migration}

Die Bedeutung der Migration für die Demographie Russlands ist unbestritten. Migranten waren und sind für Russland ein notwendiges, ergänzendes Element. Russland wies 2016 im Austausch mit allen Staaten des postsowjetischen Raumes eine positive Migrationsbilanz auf (die Zahl der Zugewanderten überstieg die der Abgewanderten; s. Tabelle 2).

Tabelle 2: Immigrationsbewegung aus postsowjetischen Staaten in die Russische Föderation

\begin{tabular}{|l|c|c|c|c|c|c|}
\hline \multirow{2}{*}{\multicolumn{1}{|c|}{ Land }} & \multicolumn{3}{|c|}{ Januar-November 2016 } & \multicolumn{3}{c|}{ Januar-November 2015 } \\
\cline { 2 - 7 } & $\begin{array}{c}\text { Zuwan- } \\
\text { derung }\end{array}$ & $\begin{array}{c}\text { Abwan- } \\
\text { derung }\end{array}$ & Bilanz & $\begin{array}{c}\text { Zuwan- } \\
\text { derung }\end{array}$ & $\begin{array}{c}\text { Abwan- } \\
\text { derung }\end{array}$ & Bilanz \\
Aserbaidschan & 21.800 & 12.121 & +9.679 & 22.079 & 12.441 & +9.638 \\
Armenien & 40.056 & 29.250 & +10.806 & 41.915 & 22.857 & +19.058 \\
Belarus & 13.443 & 11.473 & +1.970 & 16.343 & 11.802 & +4.541 \\
Kasachstan & 63.077 & 29.440 & +33.637 & 59.553 & 28.076 & +31.477 \\
Kirgistan & 25.539 & 15.031 & +10.508 & 23.229 & 14.906 & +8.323 \\
Moldau & 29.515 & 16.185 & +13.330 & 30.799 & 15.001 & +15.798 \\
Tadschikistan & 4.8038 & 23.155 & +24.883 & 43.306 & 34.260 & +9.046 \\
Turkmenistan & 6.404 & 4.437 & +1.967 & 5.798 & 3.810 & +1.988 \\
Usbekistan & 56.006 & 37.603 & +18.403 & 68.513 & 90.146 & -21.633 \\
Ukraine & 163.033 & 52.928 & +110.105 & 174.368 & 43.549 & +13.0819 \\
\hline
\end{tabular}

Quelle: Angaben von Rosstat für Januar-November 2016 und Januar-November 2015 
Die derzeitige Entwicklung der Migration nach Russland verläuft pendelartig. Arbeitsmigranten sehen in Russland keine neue Heimat und betrachten das Land lediglich als Einkommensquelle und/oder Beschäftigungsort. So verwundert es nicht, dass ein großer Teil der 2016 nach Russland eingereisten ausländischen Staatsangehörigen (4.284.181 Personen) als Aufenthaltszweck »Arbeit« angaben; "Tourismus" wurde von 2.245.217 Personen angegeben, private Zwecke oder Familienzusammenführung 1.907.378, Studium und Ausbildung von 406.052, und 835.082 Personen nannten andere Zwecke, darunter Beantragung eines Flüchtlingsstatus, vorübergehende Flucht und oder Teilnahme am staatlichen Programm zur Umsiedlung von Landsleuten (Statistische Daten des Innenministeriums zur Migrationssituation im Jahr 2016; s. <https://xn--blaew.xn--plai/Deljatelnost/statistics/migracionnaya/item/9359228/>[russ.]).

Vor der russisch-ukrainischen Krise, dem fallenden Rubelkurs, der wirtschaftlichen Stagnation sind zentralasiatische Staaten (Tadschikistan, Usbekistan und Kirgistan) die Hauptherkunftsländer von Migranten nach Russland gewesen. Jeder zweite Einwohner Tadschikistans (insgesamt $53 \%$ ) und jeder dritte Einwohner Kirgistans (insgesamt $38 \%$ ) orientierten sich auf eine Immigration nach Russland, um Arbeit zu suchen, eine Ausbildung und/oder einen neuen Wohnsitz zu erhalten (Integrationsbarometer der Eurasischen Entwicklungsbank, 2015; s. <http://www.eabr.org/ general//upload/EDB_Centre_Analytical_Report_33_Full_Rus.pdf> [russ.]). Erst in den Jahren 2014-2015 wurde die Migration aus Zentralasien von den Migrationsbewegungen aus der Ukraine verdrängt. Mit Stand vom 1. Januar 2016 waren auf dem Gebiet der Russischen Föderation 531.471 Bürger Aserbaidschans, 523.124 Bürger Armeniens, 741.453 Bürger von Belarus, 613.067 Kasachstaner, 582.863 Kirgistaner, 490.844 Bürger Moldaus, 999.035 Tadschikistaner, 1.779.002 Usbekistaner und 2.581.380 Bürger der Ukraine registriert (Aufenthalt von Staatsangehörigen der GUS-Staaten, Stand 1.10.2016, Statistische Daten der Hauptverwaltung für Migrationsfragen des Innenministeriums (GUWM MWD RF) und der »Zentralen Datenbank zur Registrierung ausländischer Staatsangehöriger und Staatenloser«, ZBDUIG).

Gegenwärtig ist die Ukraine weiterhin das Herkunftsland, aus dem die meisten Zuwanderer nach Russland stammen. Zu erwähnen ist hier, dass humanitäre Migration (Flüchtlinge und Personen, die vorübergehend Zuflucht suchen), auch aus der Ukraine, für Russland keine dominante Migrationsbewegung darstellt.

Tabelle 3: Anzahl der Bürger postsowjetischer Staaten, die 2010-2016 in Russland einen Flüchtlingsstatus erlangt haben

\begin{tabular}{|l|r|r|r|r|r|r|r|}
\hline & 2010 & 2011 & 2012 & 2013 & 2014 & 2015 & 2016 \\
Aserbaidschan & 15 & 11 & 11 & 9 & 7 & 7 & 9 \\
Armenien & - & - & - & - & - & - & - \\
Belarus & 1 & 1 & 2 & - & - & - & - \\
Estland & - & - & - & - & - & - & - \\
Georgien & 181 & 152 & 112 & 87 & 65 & 65 & 52 \\
Kasachstan & - & - & - & - & 1 & 1 & 1 \\
Kirgistan & 2 & 7 & 5 & 4 & 4 & 4 & 3 \\
Lettland & 2 & 2 & 2 & 2 & 1 & 1 & 2 \\
Litauen & - & - & - & - & - & 1 & 3 \\
Moldau & 2 & 2 & 1 & 1 & 1 & 4 & 10 \\
Tadschikistan & 8 & 10 & 8 & 12 & 11 & 11 & 10 \\
Turkmenistan & 1 & 2 & 2 & 1 & - & - & - \\
Usbekistan & 9 & 9 & 11 & 12 & 19 & 19 & 19 \\
Ukraine & 5 & 5 & 5 & 5 & 5 & 227 & 273 \\
Insgesamt, einschließlich der & 779 & 801 & 802 & 763 & 632 & 790 & 770 \\
Staatsangehörigen anderer & & & & & & \\
Staaten & & & & & & \\
\hline
\end{tabular}

Quelle: Statistische Daten des Föderalen Migrationsdienstes (FMS), des Innenministeriums (MWD) und der Föderalen Statistikbehörde Rosstat 
Tabelle 4: Anzahl der Bürger postsowjetischer Staaten, die 2010-2016 auf dem Gebiet der Russischen Föderation ein vorübergehendes Bleiberecht als befristete Asylsuchende erhalten haben

\begin{tabular}{|c|c|c|c|c|c|c|c|}
\hline & 2010 & 2011 & 2012 & 2013 & 2014 & 2015 & 2016 \\
\hline Abchasien* & - & - & - & - & 1 & 3 & 2 \\
\hline Aserbaidschan & 16 & 5 & 9 & 10 & 7 & 5 & 9 \\
\hline Armenien & - & - & - & 1 & 1 & 2 & 3 \\
\hline Belarus & - & - & - & 2 & 2 & - & - \\
\hline Estland & 1 & - & 1 & 2 & 1 & - & - \\
\hline Georgien ** & 2.149 & 2.326 & 1.787 & 1.317 & 699 & 457 & 292 \\
\hline Kasachstan & 1 & 3 & 1 & 3 & 3 & 4 & 4 \\
\hline Kirgistan & 1 & 1 & 19 & 38 & 30 & 33 & 48 \\
\hline Lettland & - & - & - & - & 1 & 1 & 4 \\
\hline Litauen & - & - & - & - & - & - & - \\
\hline Moldau & 2 & 2 & 3 & 7 & 7 & 8 & 14 \\
\hline Tadschikistan & 15 & 19 & 9 & 16 & 6 & 11 & 14 \\
\hline Turkmenistan & 10 & 6 & 4 & 14 & 10 & 10 & 12 \\
\hline Usbekistan & 52 & 69 & 50 & 68 & 87 & 91 & 79 \\
\hline Ukraine & 2 & 10 & 1 & - & - & 234.360 & 311.134 \\
\hline $\begin{array}{l}\text { Insgesamt, } \\
\text { einschließlich } \\
\text { Bürger anderer } \\
\text { Staaten }\end{array}$ & 3.425 & 3.726 & 3.036 & 2.415 & 2.822 & 237.780 & 313.707 \\
\hline
\end{tabular}

Quelle: Statistische Daten des Föderalen Migrationsdienstes (FMS), des Innenministeriums (MWD) und der Föderalen Statistikbehörde Rosstat

* Russland hat 2008 offiziell die Unabhängigkeit von Abchasien und Südossetien anerkannt.

** Ohne Abchasien und Südossetien

Das heutige Russland braucht Migranten - zur Verbesserung der demographischen Bilanz des Landes, zur Umsetzung seiner Pflichten bei der sozialen Fürsorge und zur Auffüllung der Arbeitskräfteressourcen. Der Ansicht von Sergej Aleksaschenko zufolge wird sich das Arbeitskräftereservoir des Landes bis 2025 um 18-19 Millionen verringern und das Verhältnis von erwerbsfähiger und nicht erwerbsfähiger Bevölkerung höchst kritische Dimensionen erreichen: bis 2022 dürfte es 2:1 betragen und bis 2045 auf 1,6:1 zurückgehen (Aleksaschenko, S.: Kak wymirajet Rossija: wywody is nowogo demografitscheskogo prognosa, 30. 01. 2015; <http://daily.rbc.ru/opinions/economics/30/01/2015/54c8d2 459a7947498564d371\#\%5Blenta> [russ.]).

Allerdings repräsentieren die in Russland eigentlich benötigten Migranten und die tatsächlich eintreffenden Arbeitsmigranten zwei absolut entgegengesetzte Migrationsprofile. Über 90 Prozent der Immigranten kommen aus Ländern, in denen das Durchschnittsniveau der kognitiven Fertigkeiten der Arbeitskräfte niedriger ist als in Russland (Weltbank, 2016, <http://pubdocs.worldbank.org/en/184311484167004822/Dec27-SCD-paper-eng.pdf> [engl.], S. 98; Weltbank, 2015, <https://publications.hse.ru/books/147705451> [russ., S. 12.]).

Das erzeugt zusätzliche Spannungsfaktoren auf dem russischen Arbeitsmarkt, insbesondere im Bereich der geringund unqualifizierten Beschäftigung. Schließlich verstärkt sich die Entwicklung sinkender Fertigkeitsniveaus sowie des Rückgangs beruflicher und bildungsbezogener Eignung auch unter den Russen selbst.

Nach Einschätzung von Rostislaw Kapeljuschnikow und Anna Lukjanowa sind die Bürger Russlands mit ihrem beruflichen und Bildungskapital erheblich unzufrieden und um ihre Wettbewerbsfähigkeit besorgt. Bei jeder zehnten höheren Fachkraft und bei jedem dritten geringqualifizierten Beschäftigten (vorwiegend in der Landwirtschaft, der Leicht- und Lebensmittelindustrie) sind die Aneignung neuen Wissens und neuer Fertigkeiten auf dem Arbeitsmarkt nicht erforderlich (Kapeljuschnikow, R. I., Lukjanow, A. L., 2009 <https://www.hse.ru/data/2011/01/13/1208022144/ Kapelushkin_Final_Web.pdf> [russ.], S. 37). Die Immigrationsbewegungen tragen gegenwärtig nicht zu einer Besei- 
tigung des Mangels an Fertigkeiten auf dem russischen Arbeitsmarkt bei und werden zu einer sozialen Herausforderung, bei der nicht zuletzt die derzeit betriebene Migrationspolitik ein störender Faktor ist.

\section{Institutionen des Migrationsrechts als Instrumente der Außenpolitik Russlands}

Die Zahlenmäßig geringen und niedrigqualifizierten Zuwanderungsströme können die gegenwärtigen demografischen und sozialen Herausforderungen Russlands nicht lösen. Die Schwierigkeit besteht darin, dass ein in erster Linie geopolitisch geprägtes Migrationsmanagement andere Ziele verfolgt, als den demographischen Wandel effektiv zu kompensieren. Gegenwärtig reist der größte Teil der Migranten nach Russland aus wirtschaftlichen Gründen ein: Hohe Arbeitslosigkeit, fehlende Bildungschancen, Armut und Frustration treiben Bürger der postsowjetischen Staaten in sehr viel höherem Maße aus ihrer Heimat, als militärische Konflikte, schlechte Regierungsführung oder Auswirkungen des Klimawandels. Um diese Migrationsströme effektiv zu steuern, werden Regulationsmechanismen benötigt, die stärker wirtschaftliche oder demographische Aspekte berücksichtigen, als es das derzeit vorwiegend geopolitisch ausgerichtete Migrationsmanagement gewährleistet. In den letzten Jahren wird die Steuerung der Migration nach Russland und deren rechtliche Ausgestaltung im Handbetrieb vollzogen, wobei die Institutionen des Migrationsrechts - wie Erteilung eines Visums, Erteilung einer Arbeitserlaubnis, Anerkennung des Flüchtlingsstatus oder Vor-/Nachteile beim Einbürgerungsprozess - immer öfter zu Instrumenten der Außenpolitik geraten. Hierfür gibt es eine ganze Reihe Beispiele.

Die Abkühlung der russisch-belorussischen Beziehungen im Januar 2017 wurde durch die Einführung eines neuen Grenzregimes in den Gebieten Brjansk, Pskow und Smolensk entlang der russisch-belorussischen Grenze durch Russland - als Antwort auf eine von Belarus erlassene Visafreiheit für 80 Staaten, einschließend aller Länder der Europäischen Union, Brasiliens, Indonesiens, der USA, Japans usw. - versinnbildlicht. Im Widerspruch zu dem Abkommen von 2006 zwischen Russland und Belarus über Freizügigkeit sowie die freie Wahl des Aufenthaltsortes und Wohnsitzes auf dem Gebiet der beiden Staaten wird aufgrund von Anordnungen des Direktors des FSB vom Januar 2017 eine Kontrolle der Einreise (des Verkehrs) von Fahrzeugen und Privatpersonen durchgeführt werden (Verfügungen des FSB Nr. 301-303 vom 26. Januar 2017).

Die politischen Spannungen in den russisch-ukrainischen Beziehungen hatten ebenfalls ihre Folgen. Durch den Erlass des Präsidenten Russlands vom 18. Februar 2017 („Erlass über die Anerkennung von Dokumenten, die Bürgern der Ukraine und Staatenlosen, die auf dem Territorium bestimmter Teile der Gebiete Donezk und Lugansk der Ukraine ansässig sind « [russ.], <http://kremlin.ru/acts/news/53895>) erhielten die von Russland de jure nicht anerkannten Republiken - die "Volksrepublik Donezk« (DNR) und die "Volksrepublik Lugansk« (LNR) - de facto eine Anerkennung der Dokumente, die durch diese Republiken ausgestellt wurden. Persönlichkeitsnachweise der LNR und der DNR, seien es nun Pässe, Führerscheine, Urkunden oder Bescheinigungen über die Geburt, den Tod, die Namensänderung, eine Ehe oder deren Auflösung, die durch Behörden dieser Republiken ausgestellt wurden, erwirken nun offiziell das Recht, sich auf dem Gebiet der Russischen Föderation zu bewegen, Flug-, Eisenbahn- und Fernbustickets zu erwerben, sich bei russischen Bildungseinrichtungen einzuschreiben usw.

Der russisch-türkische Konflikt hat das bisherige Migrationsmanagement Russlands gegenüber der Türkei auf den Kopf gestellt. Gemäß dem Erlass des Präsidenten Russlands vom 28. November 2015 sind russische Arbeitgeber nicht mehr berechtigt, auf dem Gebiet der Russischen Föderation türkische Staatsangehörige einzustellen, die Ende 2015 nicht in einem rechtlichen oder Arbeitsverhältnis zu russischen Arbeitgebern standen (Erlass des Präsidenten Nr. 583 vom 28. 11. 2015). Diese Einschränkungen sind nach wie vor gültig. Dass das Migrationsmanagement den Interessen des Landes dienen soll, ist nichts Neues. Allerdings sind einige Tendenzen, etwa der Einsatz des Instruments der Staatsbürgerschaft zu außenpolitischen Zwecken, beunruhigend und verdienen eine besondere Beachtung der Experten.

Im Dezember 2016 gab es einen Vorstoß der Duma-Abgeordneten Jaroslaw Nilow, Alexej Didenko, Alexandr Scherin und Sergej Iwanow (alle LDPR), durch den die Zuerkennung der russischen Staatsbürgerschaft für ausländische Staatsangehörige und Staatenlose erleichtert werden soll, falls bei einem Elternteil der Betroffenen in der Geburtsurkunde als Nationalität »russisch" vermerkt ist (Gesetzentwurf Nr. 54735-7). In der Erläuterung zum Gesetzentwurf, die vom Duma-Ausschuss für Staatsaufbau und Gesetzgebung der Russischen Föderation vorgelegt wurde, fordern die Parlamentarier »reale Maßnahmen zum Schutz der [ethnisch] russischen Bevölkerung, indem [diesen Menschen] die ungehinderte Einreise nach Russland ermöglicht wird und [sie] in kürzester Zeit die russische Staatsbürgerschaft erhalten«, da "nationalistische ukrainische Bewegungen gegen die russischsprachige Bevölkerung kämpfen«, "Einwohnern russischer Herkunft die ukrainische Staatsangehörigkeit entzogen wird» und »die Rechte und Freiheiten (das Recht auf Muttersprache, das Recht auf den Erhalt muttersprachlicher Bildung, politische Rechte) der [ethnisch] russischen Bevölkerung unter den gegebenen Umständen verletzt werden« (s. die Erläu- 
terung: <http://asozd2.duma.gov.ru/main.nsf/(ViewDoc)?Openagent\&addwork/scans.nsf/ID\&92FD8CB9FF6FE $165432580890042 \mathrm{FF} 8 \mathrm{~A}>$ [russ.])

Russische Parlamentarier, die ein Interesse an einer Rückkehr ethnischer Russen zeigen, haben eine Reihe von Gesetzesentwürfen angekündigt, durch die das Verfahren für den Erhalt der russischen Staatsangehörigkeit durch Landsleute, Träger der russischen Sprache und der russischen Kultur sowie durch direkte Nachkommen von Personen vereinfacht werden soll, die im Russischen Reich oder der Sowjetunion geboren wurden (Gesetzentwurf Nr. 69201-7). Diesem Gesetzentwurf von Konstantin Satulin ("Einiges Russland «) vom Januar 2017 zufolge sollten Personen mit Herkunft aus den "historisch [ethnisch] russischen Ländern« das Recht haben, ein vereinfachtes Verfahren zur Anerkennung als Träger der russischen Sprache durch die »Kommission zur Anerkennung eines ausländischen Staatsangehörigen oder Staatenlosen als Träger der russischen Sprache« zu durchlaufen (das Verfahren wird durch Abs. 1 des 2014 eingeführten Paragraphen 33.1 des Gesetzes ॥Über die Staatsbürgerschaft der Russischen Föderation « vorgeschrieben) und von der Vorlage von Dokumenten der zuständigen ausländischen Behörden über das Verlassen der ausländischen Staatsangehörigkeit (Vorschrift nach Abs. $2.1 \$ 14$ des Staatsbürgerschaftsgesetzes) befreit werden.

Nach Ansicht des Duma-Ausschusses für Staatsaufbau und Gesetzgebung sind »die Verfahren zum Erhalt eines Niederlassungstitels und der russischen Staatsangehörigkeit vom Voluntarismus ausländischer Bürokraten, politischen Problemen und den aktuellen Beziehungen zwischen Russland und dem Staat, dessen Staatsangehörigkeit der Träger der russischen Sprache innehat, abhängig [...] Usbekistan erkennt die Krim nicht als Teil Russlands an und in der Botschaft dieses Landes werden Anträge auf eine Aufgabe der Staatsangehörigkeit durch Bürger Usbekistans, die auf der Krim als Träger der russischen Sprache anerkannt wurden, nicht entgegengenommen; das verbaut diesen das Recht auf den Erhalt eines Niederlassungstitels und die russische Staatsangehörigkeit. Bürgern der Ukraine, die Träger der russischen Sprache sind und sich auf der Krim aufhalten, wird das Recht auf die russische Staatsangehörigkeit ebenfalls praktisch verweigert« (Erläuterung zum Gesetzentwurf Nr. 69201-7; <http://asozd2.duma.gov.ru/main.nsf/ (ViewDoc)?Openagent\&addwork/scans.nsf/ID\&38D9AEEEA790B9864325809900454308> [russ.]).

Diese Initiativen von Parlamentariern sind mit aller Vorsicht zu genießen - die Frage ist noch nicht entschieden. Zum einen ist die Quote einer erfolgreichen Verabschiedung als Gesetz bei solchen Initiativen nicht hoch. Allerdings erhöht die stetig wachsende Zahl solcher Gesetzesinitiativen in der siebten Staatsduma die Wahrscheinlichkeit, dass eine von ihnen Realität wird.

\section{Fazit}

Die demografische Zukunft Russlands ist von der Qualität und Quantität der Einwanderer abhängig. Daher sind die Steuerung der demographischen Bilanz, die Vermeidung eines Bevölkerungsschwundes und eine Optimierung der Zuwanderungsströme die wichtigsten Aufgaben der staatlichen Verwaltung im heutigen Russland. Wer kommt - und wer geht -, sind Fragen, mit denen sich Russland in den kommenden Jahren stark zu beschäftigen haben wird. Es ist zu betonen, dass jede Entscheidung im Bereich des Migrationsmanagements sowie politisch ausgerichtete Migrationsmaßnahmen zur Kompensation des demographischen Wandels einen Preis verlangen, den die kommende Generation Russlands zu zahlen haben wird. Die Exekutive und die Legislative des Landes gelangen nur schwer zu einer solchen Erkenntnis. Derzeit dominieren in jedem Bereich der Staatsgewalt Russlands die sich wandelnden außenpolitischen Intentionen, weshalb das Migrationsmanagement des Landes auch kaum die Möglichkeit hat, sich adäquat an den demographischen und sozialen Herausforderungen auszurichten.

\section{Übersetzung aus dem Russischen: Hartmut Schröder}

\section{Über die Autorin}

Olga R. Gulina promovierte 2010 an der Universität Potsdam in Migration Studies und 2002 zur Doktorin der Rechtswissenschaften an der Baschkirischen Staatlichen Universität. Sie ist Mitbegründerin des Institutes on Migration Policy (RUSMPI). 


\section{Immigration nach Russland}

Grafik 4: Gibt es an Ihrem Wohnort viele oder wenige Migranten?

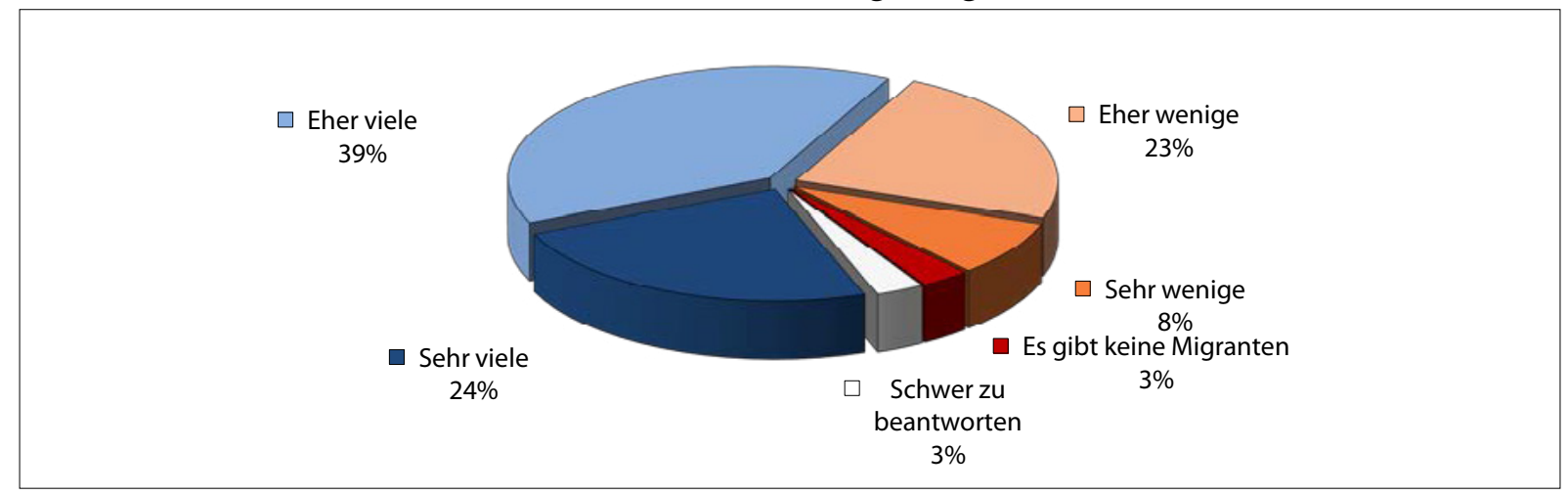

Quelle: Umfragen des WZIOM vom 17.-24. Januar 2016, <http://wciom.ru/index.php?id=236\&uid=115969>, 29. November 2016

Grafik 5: Welcher Ansicht stimmen Sie eher zu?

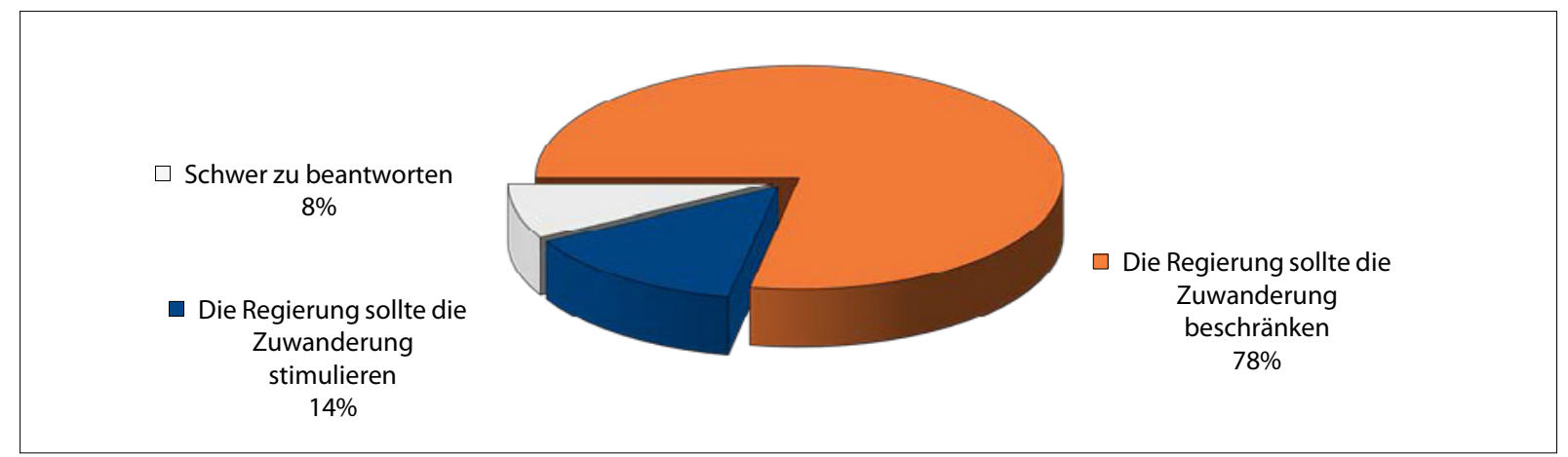

Quelle: Umfragen des WZIOM vom 17.-24. Januar 2016, <http://wciom.ru/index.php?id=236\&uid=115969>, 29. November 2016

Grafik 6: Welcher Ansicht stimmen Sie eher zu?

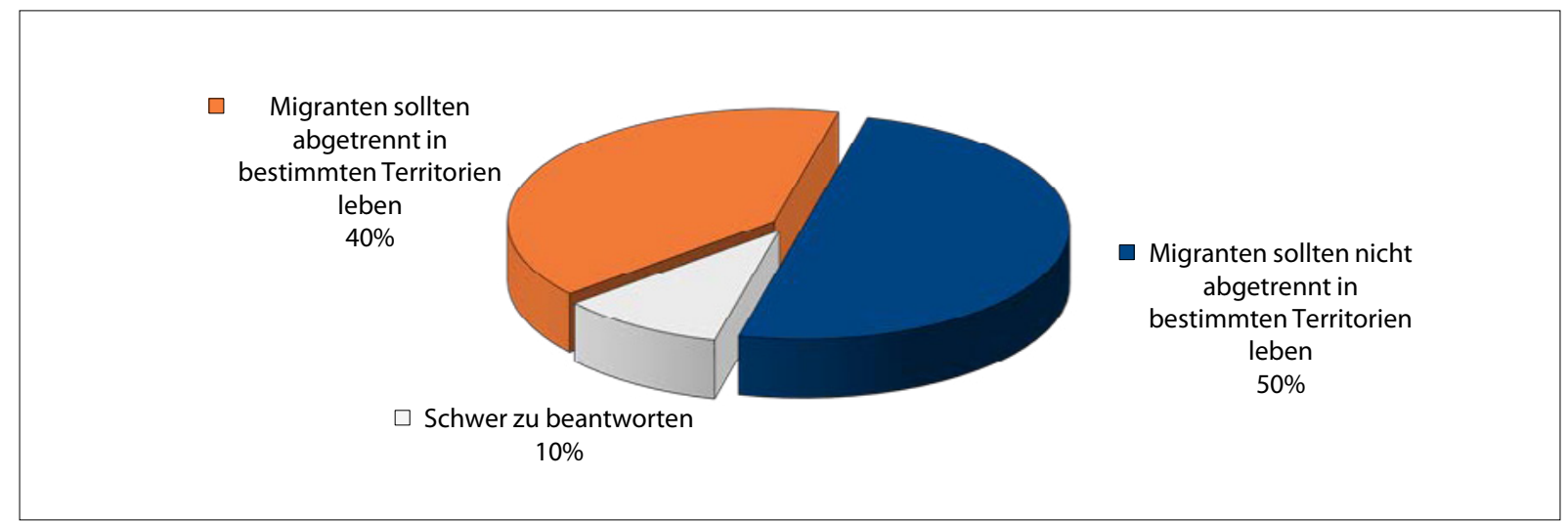

Quelle: Umfragen des WZIOM vom 17.-24. Januar 2016, <http://wciom.ru/index.php?id=236\&uid=115969>, 29. November 2016 


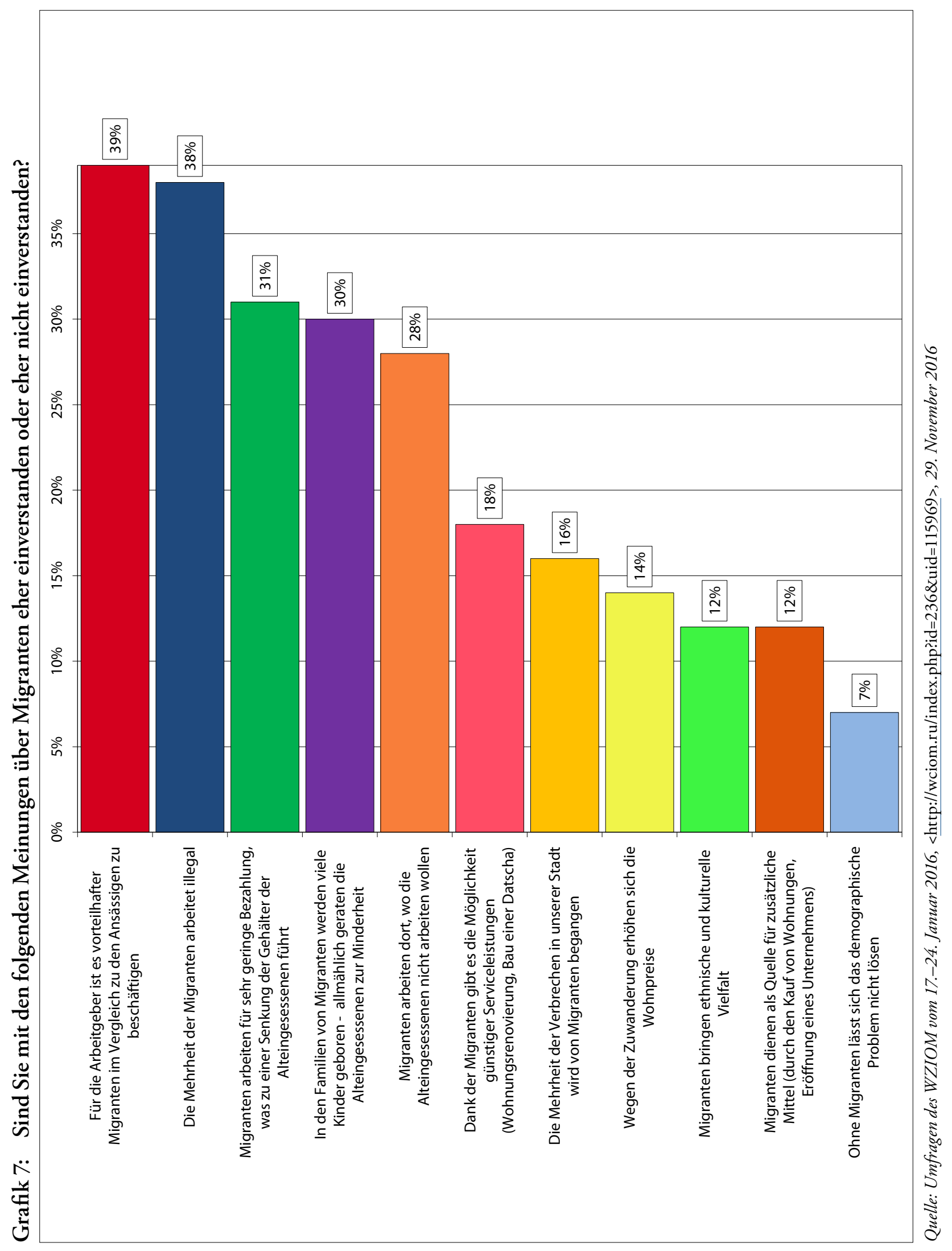


Grafik 8: Was denken Sie, sollte das Verfahren zum Erhalt der Aufenthaltsgenehmigung und der russischen Staatsbürgerschaft für Migranten aus den GUS-Staaten vereinfacht, erschwert oder unverändert bleiben?

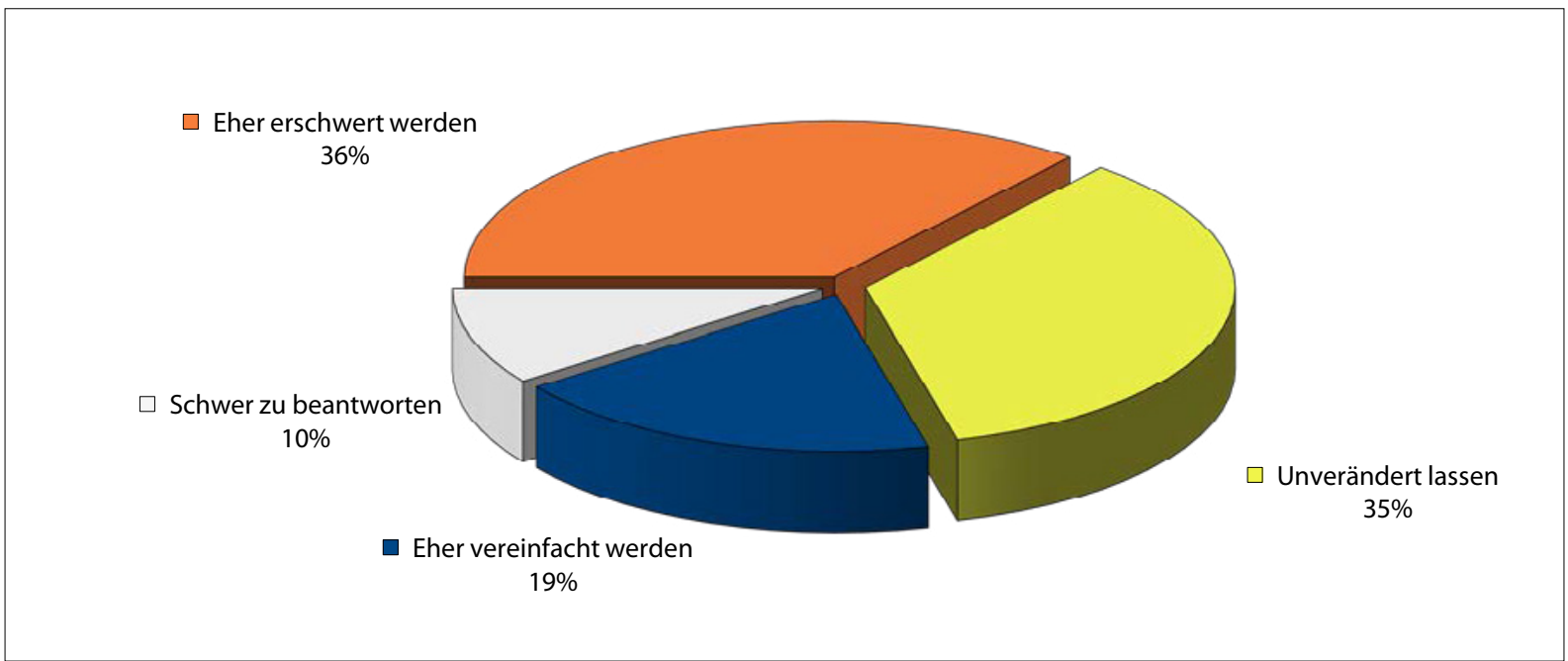

Quelle: Umfragen des WZIOM vom 17.-18. Dezember 2016, <http://wciom.ru/index.php?id=236\&uid=116061>, 10. Februar 2017

Grafik 9: Unterstützen Sie den Vorschlag einer Amnestie für die Migranten aus den GUSStaaten, die sich schon lange entgegen der gesetzlichen Bestimmungen in Russland aufhalten, oder unterstützen Sie ihn nicht?

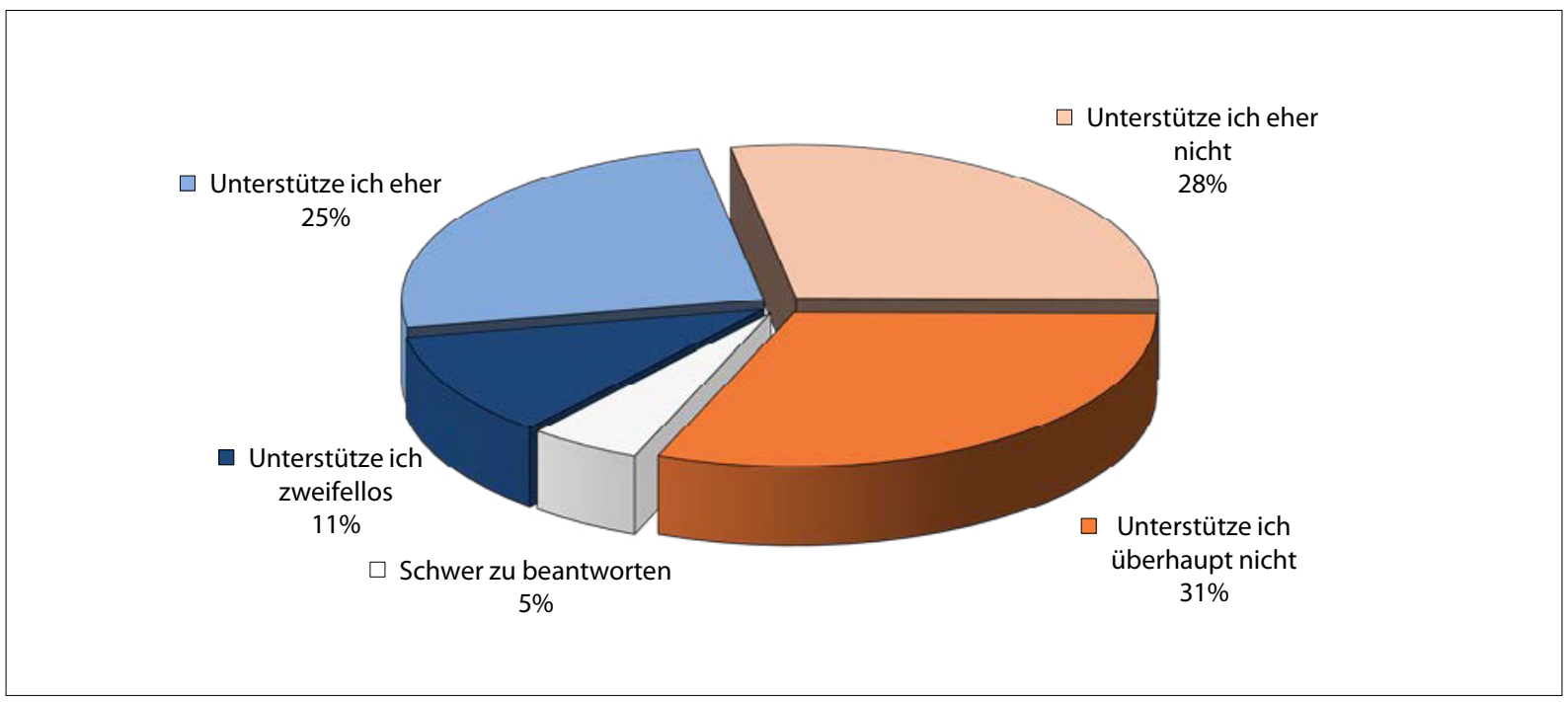

Quelle: Umfragen des WZIOM vom 17.-18. Dezember 2016, <http://wciom.ru/index.php?id=236\&uid=116061>, 10. Februar 2017 


\section{Emigration aus Russland}

Grafik 10: Würden Sie gern dauerhaft ausreisen oder nicht?

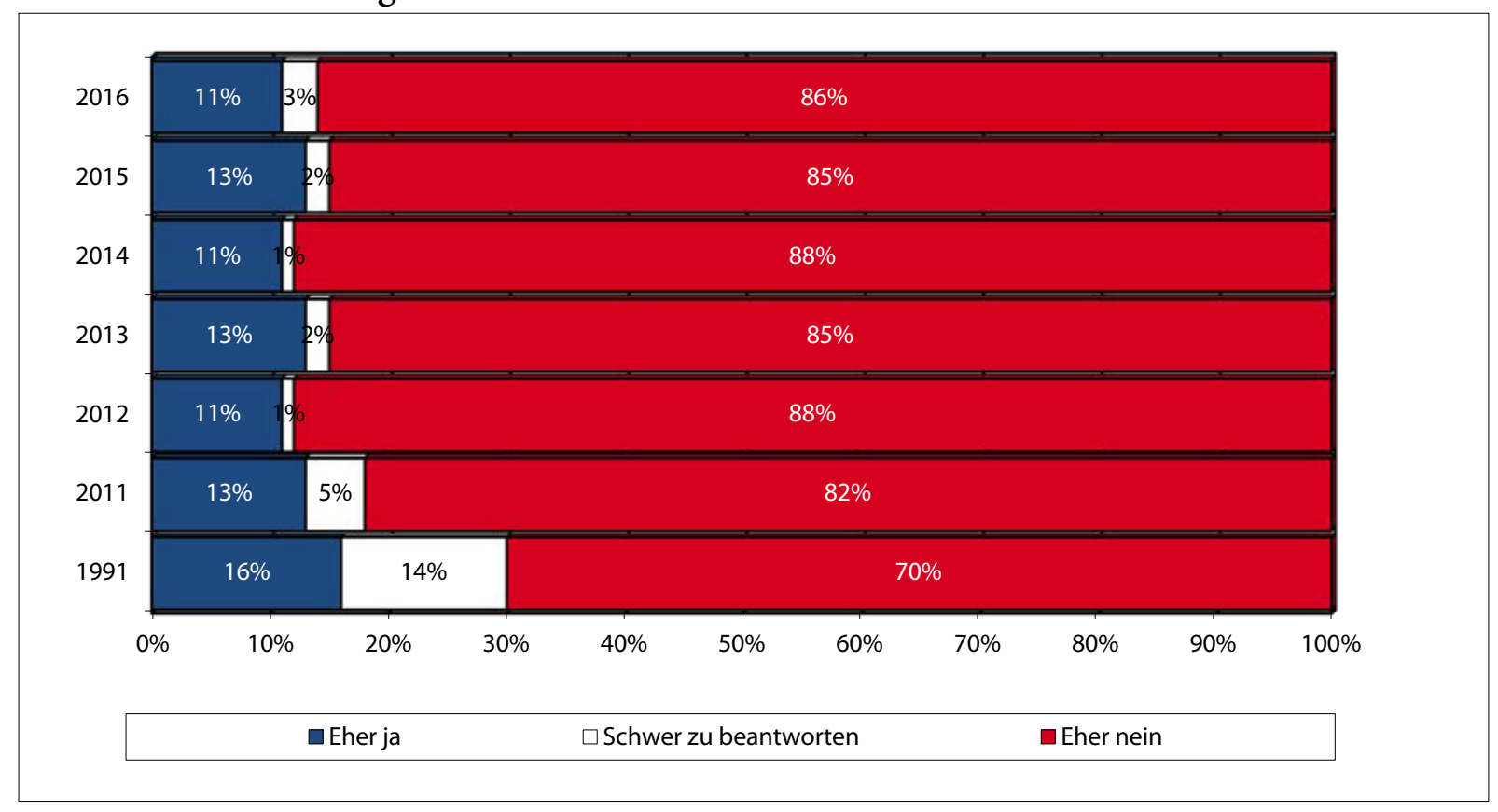

Quelle: Umfragen des WZIOM vom 8.-9. Oktober 2016, <http://wciom.ru/index.php?id=236\&uid=115921>, 26. Oktober 2016

Grafik 11: Was wäre für Ihre Kinder und Enkel besser, wenn sie erwachsen sind: in Russland zu leben oder außerhalb Russlands zu leben?

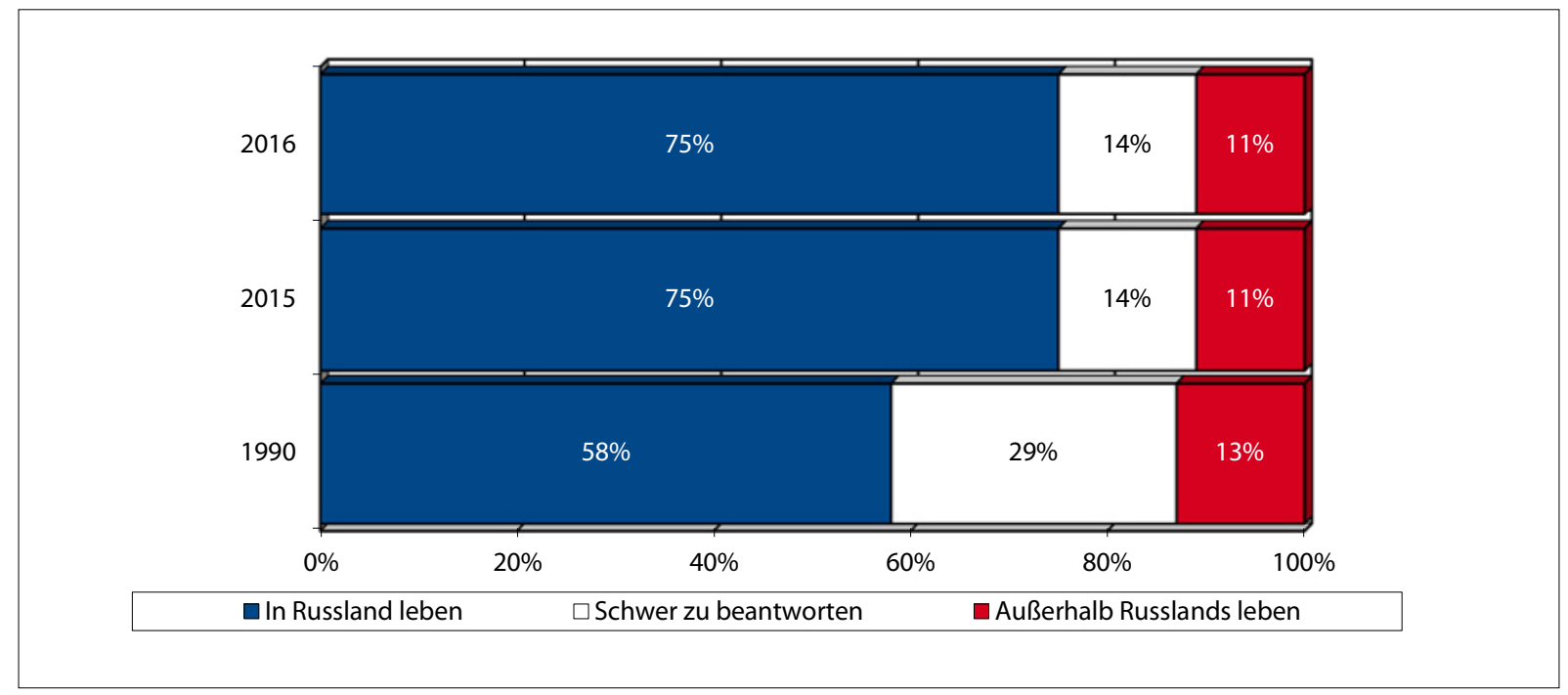

Quelle: Umfragen des WZIOM vom 8.-9. Oktober 2016, <http://wciom.ru/index.php?id=236\&uid=115921>, 26. Oktober 2016 


\section{Flüchtlingssituation in Europa und Russland}

Grafik 12: In der letzten Zeit reisen vielen Flüchtlinge aus den Ländern des Nahen Osten, darunter aus Syrien, in die Länder der EU ein. Haben Sie darüber Informationen in den Medien gesehen?

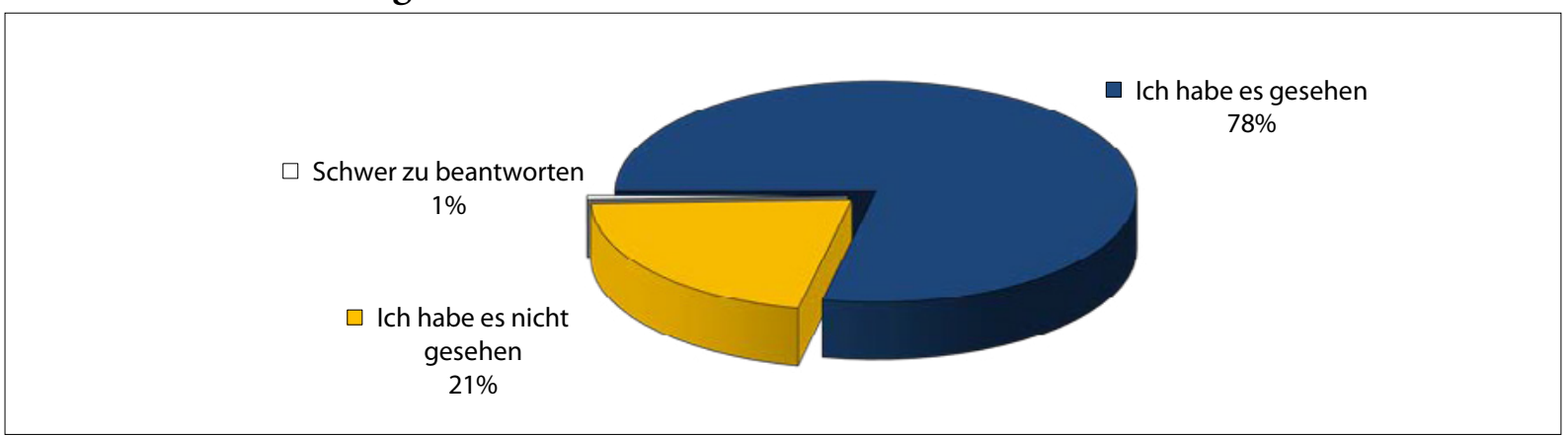

Quelle: Telefonische Umfrage von TeleFOM vom 30.-31. Januar 2016, <http://fom.ru/Mir/12514>, 11. Februar 2016

Grafik 13: Was denken Sie, sind die Länder der EU verpflichtet, Flüchtlinge aus dem Nahen Osten aufzunehmen, oder haben sie das Recht, diese abzuweisen?

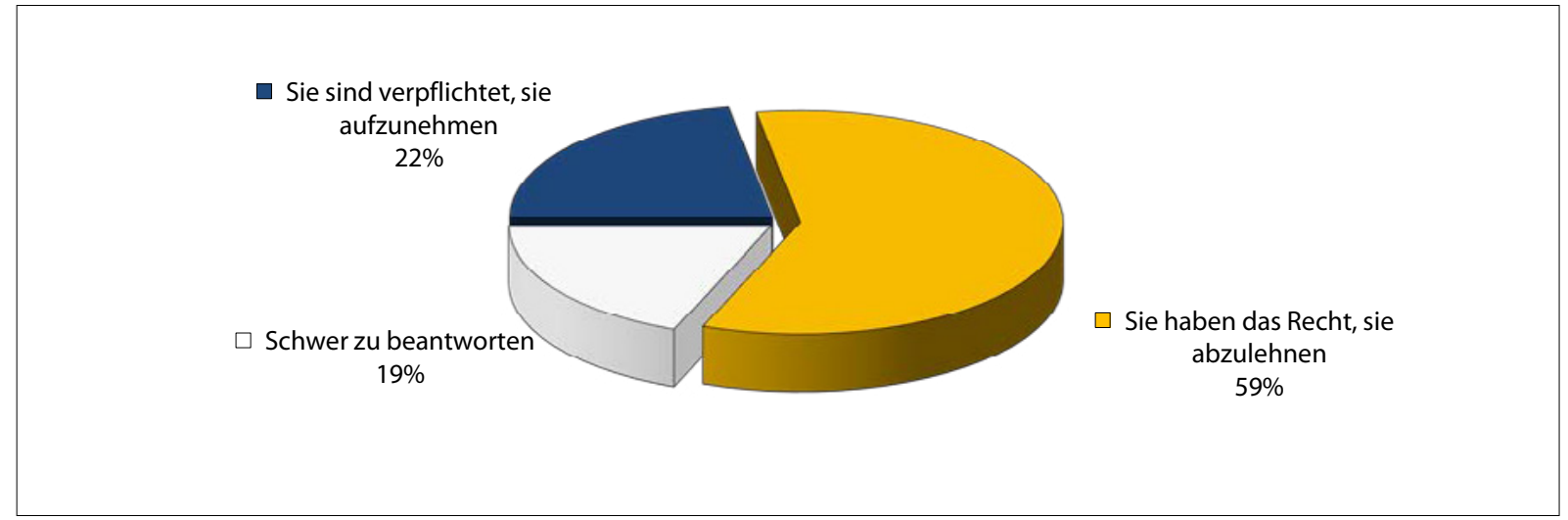

Quelle: Telefonische Umfrage von TeleFOM vom 30.-31. Januar 2016, <http://fom.ru/Mir/12514>, 11. Februar 2016

Grafik 14: Was denken Sie, falls Flüchtlinge aus dem Nahen Osten versuchen würden nach Russland zu kommen, sollten sie aufgenommen werden oder nicht?

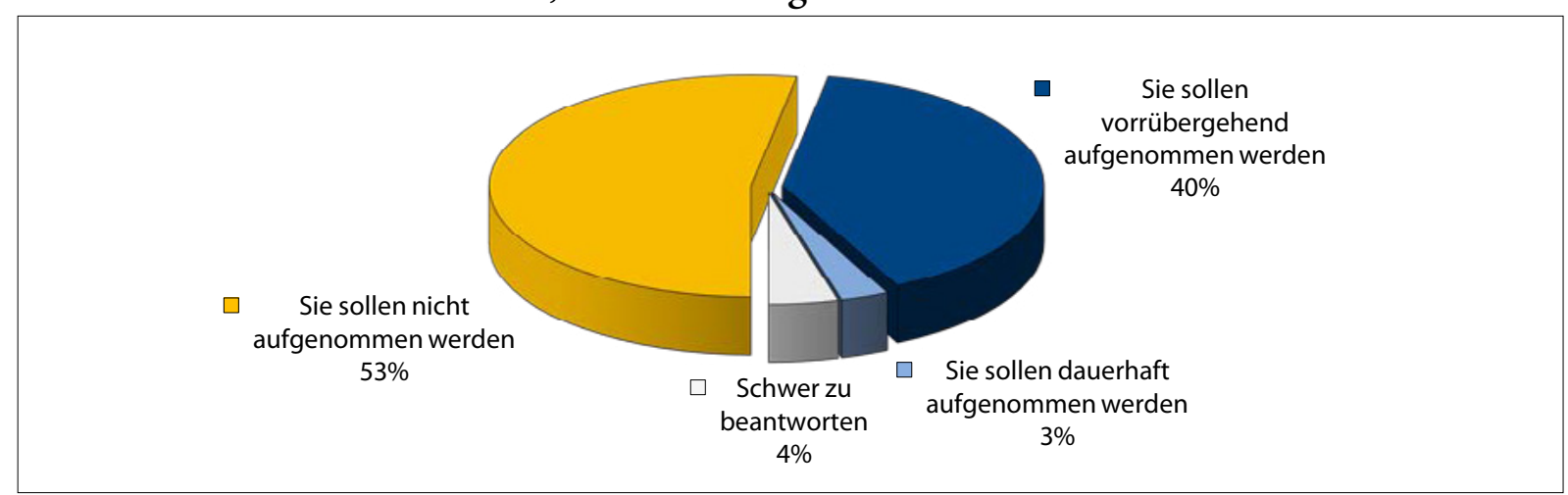

Quelle: Telefonische Umfrage von TeleFOM vom 30.-31. Januar 2016, <http://fom.ru/Mir/12514>, 11. Februar 2016 


\section{Krieg in der Ostukraine}

Grafik 15: Was denken Sie, welche Position sollte Russland im Verhältnis zu den Volksrepubliken Donezk und Lugansk einnehmen?

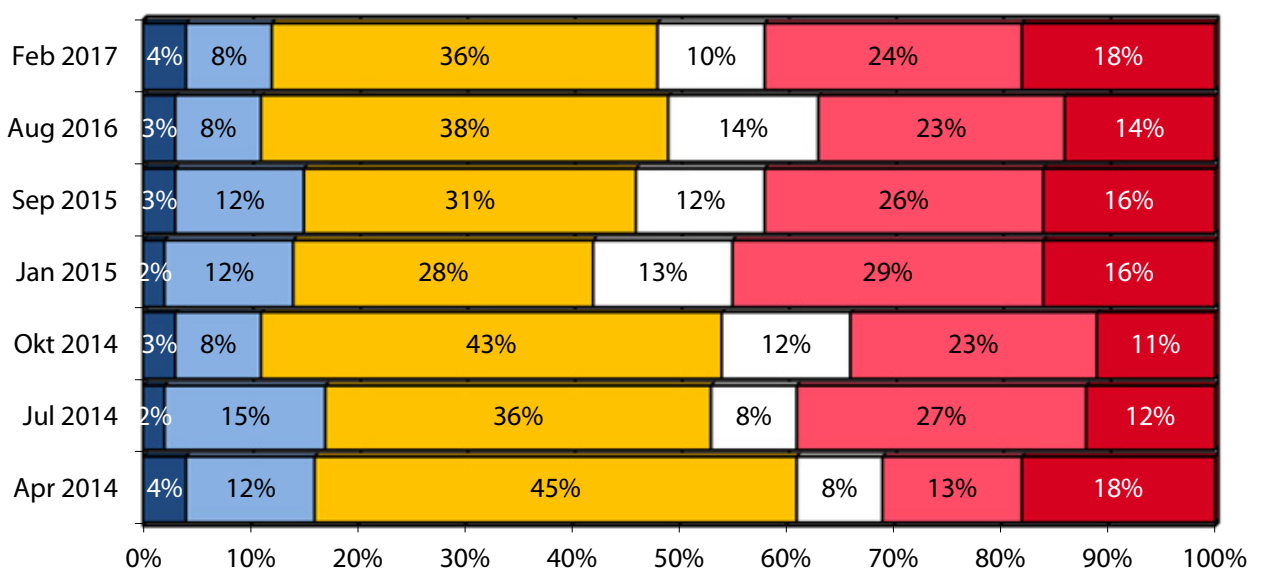

$\square$ Den Machthabenden in Kiev helfen die Kontrolle über die Territorien VRD und VRL wiederherzustellen

$\square$ Den Volksrepubliken helfen, ihre Autonomie innerhalb des ukrainischen Staates auszuweiten

$\square$ Sich nicht einmischen, Neutralität bewahren

$\square$ Schwer zu beantworten

$\square$ Die Volksrepubliken VRN und VRL als unabhängige Staaten anerkennen

Die Volksrepubliken in das Gebiet Russlands aufnehmen

Quelle: Umfragen des WZIOM vom 5.-6. Februar 2017, <http://wciom.ru/index.php?id=236\&uid=116076>, 20. Februar 2017

Grafik 16: Was denken Sie, sollte Russland jegliche Unterstützung für die Milizen im Donbass einstellen, um das Verhältnis zur Ukraine und zum Westen zu verbessern?

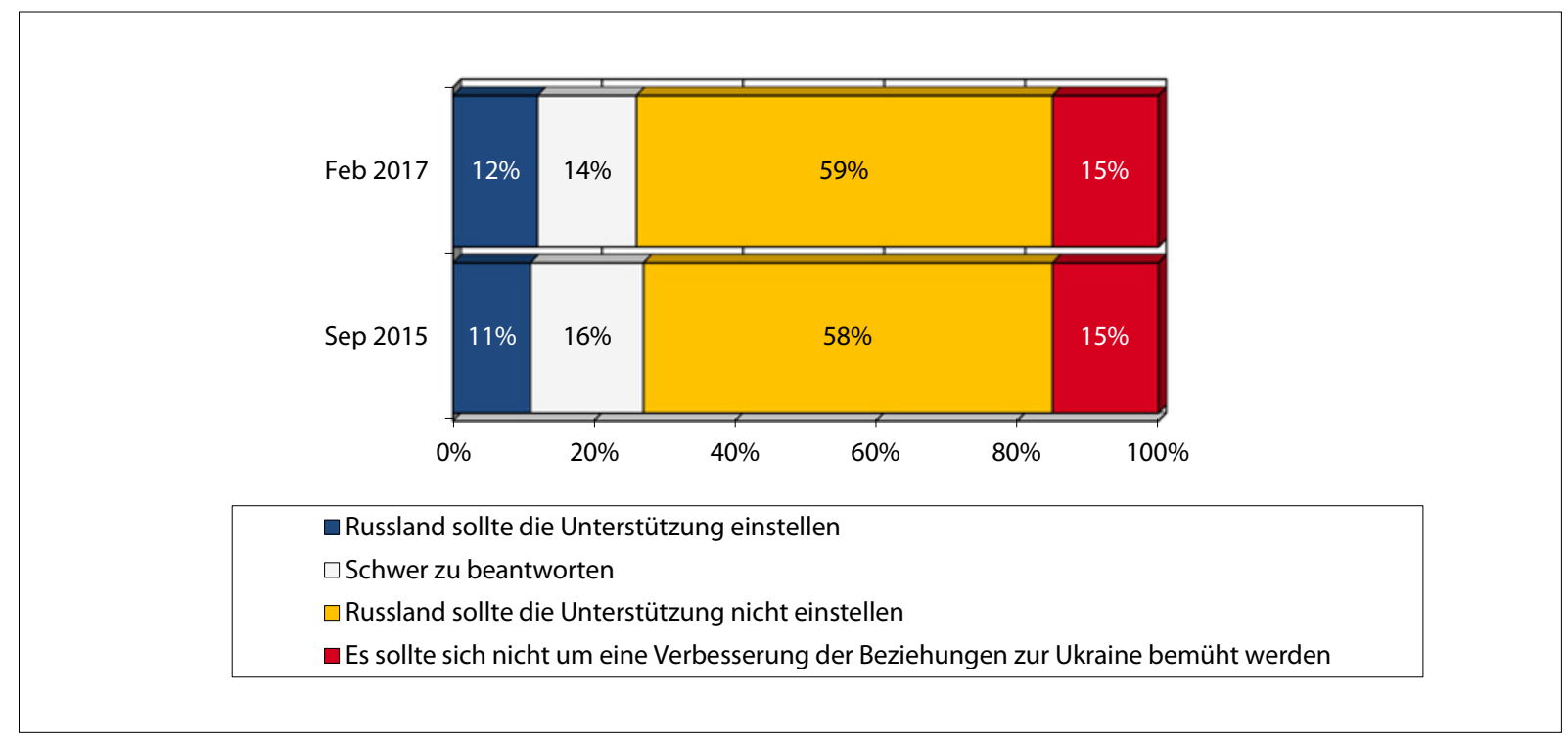

Quelle: Umfragen des WZIOM vom 5.-6. Februar 2017, <http://wciom.ru/index.php?id=236\&uid=116076>, 20. Februar 2017 


\section{Isaaks-Kathedrale}

Jens Siegert, Moskau

$\mathrm{D}$ ie Isaaks-Kathedrale in St. Petersburg, ein spätklassizistischer Kuppelbau, ist neben der Peterund-Paul-Festung und dem Winterpalast eines der Bauwerke, die das Bild der Stadt prägen. Mit einer Länge von 111 Metern, einer Breite von 97 Meter und einer Höhe von 101,50 Meter dominiert die Kirche baulich die Admiralitätsseite der Stadt. Der Durchmesser der vergoldeten Hauptkuppel beträgt 26 Meter. Da die Innenstadt von St. Petersburg von sozialistischen und postsozialistischen Hochhausbauten weitgehend verschont blieb, hat, wer den Rand der Kuppel besteigt, eine wunderbare Aussicht über die gesamte historische Stadt (das Attribut "Altstadt« verbietet sich für St. Petersburg, da die historische Stadt fast wie aus einem Guss binnen eines guten Jahrhunderts von Mitte des 18. bis Mitte des 19. Jahrhunderts gebaut wurde und sich bis heute fast vollständig so erhalten hat).

Mit der Errichtung der heutigen Isaaks-Kathedrale wurde 1818 begonnen, als nationales Denkmal an den Sieg über Napoleon. Der Vorgängerbau, die »3. IsaaksKathedrale« wurde dazu abgerissen. Erst 1858, es gab unter anderem zwei jahrelange Bauunterbrechungen wegen statischer Probleme mit dem sumpfigen Untergrund an der Newamündung, war die Kirche fertig. Nach der Oktoberrevolution wurden in der IsaaksKathedrale noch bis 1928 Gottesdienste abgehalten. 1931 richteten die Bolschewisten in der Kirche ein antireligiöses Museum ein. Damals wurde ein 91 Meter langes Foucaultsches Pendel in die Kuppel gehängt. Im Zweiten Weltkrieg diente die Isaaks-Kathedrale als Depot für Kunstgegenstände aus den um Leningrad liegenden Zarenresidenzen.

1942 wurden die fünf vergoldeten Kuppeln mit einem grünen Tarnanstrich überzogen. Die Kathedrale hatte dennoch erheblich unter dem deutschen Artilleriebeschuss zu leiden. Nach dem Krieg begannen aufwändige Restaurierungsarbeiten, die 1960 abgeschlossen wurden. Als in der Gorbatschow-Zeit in der Sowjetunion größere Spielräume für Religion entstanden, konnte 1990 wieder ein festlicher Gottesdienst abgehalten werden. Eine erneute Restaurierung der Kathedrale erfolgte in den Jahren 1994 bis 2003 anlässlich des 300 jährigen Jubiläums der Gründung von St. Petersburg. Heute werden an hohen Feiertagen Gottesdienste gefeiert. Aber vor allem ist die Kathedrale nach wie vor ein Museum und gehört dem Staat.

Anfang dieses Jahres nun entbrannte um die IsaaksKathedrale ein öffentlicher, ich würde gar sagen, ein politischer Streit. Am 10. Januar verkündete der St. Peters- burger Gouverneur Georgij Poltawtschenko, dass die Kathedrale der Russisch-Orthodoxen Kirche "zurückgegeben« werde. Diese (selbstverständlich) ohne vorherige öffentliche Debatte getroffene Entscheidung rief schnell heftigen Protest in der Stadt hervor. Schon das ist ungewöhnlich für das heutige Russland. Noch ungewöhnlicher ist, dass dieser Streit mit einem Kompromiss zu enden scheint (freilich muss später noch darauf eingegangen werden, was dieses Wort »Kompromiss» heute in Russland bedeutet).

Die Entscheidung des Stadtgouverneurs stützt sich auf ein 2010 verabschiedetes Gesetz, demzufolge anerkannten Religionsgemeinschaften ihre in der Sowjetzeit enteigneten Gebäude, Liegenschaften und sonstiger Besitz "auf Antrag zurück gegeben" werden kann. Die Betonungen liegen dabei auf "Antrag« und »kann«. Bis 2015 hatte die orthodoxe Kirche keinen Antrag gestellt. Der Staat kann die Rückgabe verweigern, wenn er dafür übergeordnete Gründe angeben kann. Wie eigentlich fast immer in solchen Fällen, blieb der Antrag öffentlich unbekannt. Häufig funktioniert derartig klandestines Vorgehen im Sinne der staatlichen Entscheider. Die Öffentlichkeit wird überrascht, der meist eher zaghafte Protest ignoriert und meist legt sich die Aufregung schnell wieder. In Fällen wie dem der Isaaks-Kathedrale hilft mitunter auch ein in der Gesellschaft weitgehend stillschweigend geteiltes Einverständnis, dass Kirchen eben zur Kirche gehören und nicht zum Staat. Doch diesmal funktionierte es nicht.

Schnell formierte sich heftiger Protest. Es gab Demonstrationen, Internet-Petitionen und auch prominente St. Petersburger wie der Regisseur Alexander Sokurow schlossen sich an. Sergej Schnurow, Frontmann der Kultband »Leningrad« veröffentlichte auf seinem Instagram-Account ein sarkastisches Gedicht, das den Wiederaufstieg des "heiligen Russland" aufs Korn nimmt (<https://www.instagram.com/p/BQnVY1TgSfg/>). Doch damit nicht genug. Auch aus dem eher kremlnahen Establishment gab es Widerspruch. Der prominenteste kam vom Direktor der Staatlichen Eremitage Michail Petrowskij. Er rief den Patriarchen der RussischOrthodoxen Kirche Kirill Ende Januar öffentlich dazu auf, den Antrag auf »Rückgabe« der Kathedrale zurückzuziehen, um »die Spaltung der Gesellschaft« zu beenden (<http://www.interfax.ru/russia/546991 $>)$.

Patriarch Kirill antwortete Mitte Februar mit einem Hirtenbrief (<http://www.patriarchia.ru/db/ text/4805764.html>). Er hob die Auseinandersetzung gleich noch eine Ebene höher. Zitat: "Einst waren die 
Zerstörung von Kirchen und der massenhafte Mord an Gläubigen eine schreckliche Seite der nationalen Spaltung. Heute muss der Friede um die Rückgabe von Kirchen die Verkörperung von Einigkeit und gegenseitigem Verzeihen sein - von Weißen und Roten, von Gläubigen und Ungläubigen, von Reichen und Armen.« Damit bezog sich Kirill deutlich auf die 100-jährige Wiederkehr des Revolutionsjahrs 1917. Wer gegen die Rückgabe der Isaaks-Kathedrale ist, ist auch gegen die Heilung der Wunden von damals, soll das wohl heißen.

Wer gegen die Rückgabe ist, ist damit, so muss geschlussfolgert werden, aber auch gegen Präsident Putin, der die Versöhnung zum Hauptmotiv der Erinnerung an die Revolutionen von 1917 in diesem Jahr erhoben hat. Der Kreml scheint jedoch, zumindest diesmal und in Bezug auf St. Petersburg, eine feinere Nase als der Patriarch zu haben. Am gleichen Tag, an dem der Hirtenbrief veröffentlicht wurde, erschienen in der Presse (mit Bezug auf "Quellen, die dem Kreml nahe stehen«) Meldungen, Poltawtschenko habe die Rückgabe der IsaaksKathedrale an die Kirche nicht mit Putin abgesprochen. Wegen der »sozialen Spannungen«, die durch die Rückgabe entstanden seien, so hieß es dort weiter, solle besser eine "gemeinsame Nutzung» der Kathedrale durch Stadt und Kirche ins Auge gefasst werden (<http://www.rbc. $\mathrm{ru} /$ politics/17/02/2017/58a6bcf79a79475a76c84e7f $>$ ).

Nun ist es, sehr vorsichtig gesagt, unwahrscheinlich, dass Poltawtschenko eine so bedeutende Entscheidung wie die Rückgabe der Isaaks-Kathedrale an die Kirche ohne Rücksprache mit dem Kreml, ja mit Putin persönlich getroffen hat (zumal dem Präsidenten, der in Leningrad geboren und aufgewachsen ist, ein großes persönliches Interesse an den Entwicklungen in der Stadt nachgesagt wird). Der Protest in St. Petersburg hat also gewirkt. Das gilt übrigens auch dann, wenn es sich, in Russland immer gern geglaubt und möglich, um ein abgekartetes Spiel handeln sollte, wenn dieser "Kompromiss" von Kreml und Kirche also von vornherein angestrebt, zumindest aber als Rückfallposition in Erwägung gezogen wurde. Auch in diesem Fall war es der (antizipierte) Protest, der eine vollständige Rückgabe verhindert hat.

Was macht den St. Petersburger Protest gegen die Rückgabe der Isaaks-Kathedrale nun so besonders, dass er nicht nur entstehen konnte, dass nicht nur alle wussten und davon ausgingen, dass er entstehen wird, sondern dass er auch noch, zumindest teilweise, erfolgreich sein könnte? Die Antwort auf diese Fragen hat zumindest zwei Teile, einen direkt auf St. Petersburg bezogenen und einen, der vielleicht nicht für das ganze Land gelten mag, aber doch immerhin für einen großen Teil.

Zum St. Petersburger Teil der Antwort. Kultur, vor allem die Stadt selbst als architektonisches Ensemble, gehört zum St. Petersburger Selbstverständnis. Die Phrase von der »kulturellen Hauptstadt Russlands» (in Abgrenzung zu Moskau) ist zwar abgenutzt, sitzt aber nichtsdestotrotz tief, nicht zuletzt, weil Moskau eben doch mit großem Abstand in fast Allem das Zentrum Russlands ist. Kultur ist wohl auch deshalb in St. Petersburg noch mehr Kultur als in Russland insgesamt. Alle Eingriffe von außen (und die Kirche dürfte hier ziemlich sicher als eine äußere Kraft aufgefasst werden) treffen auf entsprechende Abwehrreflexe. Zudem hatte der bisher letzte Sieg der St. Petersburger gegen "die da oben", die Verhinderung eines Gasprom-Wolkenkratzers am Rande der Innenstadt, ebenfalls mit dem Anblick der Stadt, ihrem Image als einmaliges, ganzheitliches Architekturensemble zu tun. Vergangene Siege machen Mut, es wieder zu versuchen. Nichts ist halt erfolgreicher als der Erfolg. Außerdem ist heute in Russland gegen den Staat direkt kaum etwas zu gewinnen, gegen die Kirche (oder eben früher gegen Gasprom) schon. Beide sind zwar sehr eng mit dem Staat verbunden, aber eben doch nicht der Staat.

Ein zweiter Grund mag in der Person von Gouverneur Poltawtschenko liegen. Er ist grau, öffentlichkeitsscheu, hat ein eher asketisches Image und ist schlicht so unbeliebt in der Stadt, wie es ein aus Moskau (!) gesandter Kommissar nur sein kann. Da hilft es kaum, dass der Entsender, Putin, ein Sohn der Stadt ist und Poltawtschenko, als Siebenjähriger mit seiner Familie zugezogen, im Grunde auch. Aufgrund ihrer Funktionen sind sie virtuell zu Moskauern geworden. Auf solche Emigranten aus St. Petersburg kann man stolz sein, weil sie es in Moskau geschafft haben, ja die Hauptstadt sogar in gewisser Weise übernommen haben. Aber eben deshalb sollten sie sich möglichst wenig in ihrer Heimatstadt einmischen.

Hinzu kommt, als dritter Grund, das Image der orthodoxen Kirche. Zwar bezeichnen sich in Umfragen über 70 Prozent der Menschen in Russland als orthodoxe Christen, aber nur drei bis vier Prozent gehen von Zeit zu Zeit, zumindest an den großen christlichen Feiertagen, zum Gottesdienst. Gar nur etwa ein Prozent sind regelmäßige Kirchgänger. Sich zur Russisch-Orthodoxen Kirche zu bekennen ist viel eher die Versicherung "ich bin Russe« als ein Glaubensbekenntnis (in diese Richtung weisen übrigens auch Untersuchungen, wie gut die Menschen die orthodoxen Glaubensmaximen kennen, nämlich nicht sehr gut; selbst viele Gläubige und sogar nicht wenige Priester offenbaren ein für die orthodoxe Hierarchie erschreckendes Niveau kanonischer Unkenntnis bis hin zu einer Nähe zu römischkatholischen Dogmen).

Wenn es um die "Rückgabe« von Dorfkirchen geht, ist das für die meisten Menschen in Russland in Ord- 
nung. Sie "gehören« für sie fraglos zur Kirche (bei allen Konflikten, die es in Einzelfällen immer wieder gibt). Etwas Anderes ist es mit einer "Staatskirche« wie der Isaaks-Kathedrale. Sie war immer mehr ein Staatssymbol als eine Kirche für Gläubige und das Gebet. Auch juristisch ist es eine kniffelige Frage, denn das vorrevolutionäre Russische Imperium kannte keine Eigentumstrennung zwischen Staat und Kirche. Der Zar war das Oberhaupt der Kirche und die Kirche durch ihn mit dem Staat untrennbar verbunden. Was heute rechtmäßig der Kirche gehört, und was dem Staat ist also vor allem eine politische und nur zweitrangig eine juristische Frage.

Soweit zu St. Petersburg, nun zum Land insgesamt. Von außen sieht es oft so aus, als sei in Putin-Land alles asphaltiert und so ruhig, wie auf dem Riesenparkplatz eines Rieseneinkaufszentrums am Sonntag (wobei dieses Bild schon deshalb schief ist weil in Russland gerade an Sonntagen auf den Riesenparkplätzen von Rieseneinkaufszentren - sehr zum Zorn der orthodoxen Kirche - die Hölle los ist). Tatsächlich ist regionaler und lokaler Protest nichts Ungewöhnliches und stellt den Staat durchaus immer wieder vor Probleme. Auch ist St. Petersburg nicht widerständiger oder widersinniger als zum Beispiel Moskau oder andere russische Städte und Regionen. Jede Stadt, jede Region hat ihre besonderen Symbole, für deren Schutz (auch vor dem Staat) viele Bürger bereit sind, auf die Straße zu gehen. Ich verweise hier nur auf ein besonders anschauliches Beispiel, den Protest gegen den Bau einer Ölpipeline am Baikalsee vorbei zum Pazifischen Ozean im Fernen Osten. Ich habe diesen Protest seinerzeit in der Zeitschrift "Osteuropa« ausführlich beschrieben (<https://www.boell.de/ sites/default/files/assets/boell.de/images/download_de/ weltweit/baikalpipeline.pdf $>$ ).
Hinzu kommt die seit Jahren schwierige wirtschaftliche Situation, die sich einfach nicht bessert. Protest gibt es an vielen Orten. Neben St. Petersburg sind das momentan (nur eine kleine, nicht repräsentative Auswahl) zum Beispiel:

- in Wladiwostok demonstrieren Arbeiter eines Rüstungsbetriebs seit Monaten für die Auszahlung ausstehender Löhne);

- in Moskau wurden im Januar Menschen verhaftet, die Proteste gegen den Bau einer Kirche in einem städtischen Park vor ihrer Haustür organisiert hatten;

- in Jekaterinburg bildeten Mitte Februar Anwohner eine Menschenkette um einen Teich in der Stadt, der ebenfalls einer neuen Kirche weichen soll;

- im Gebiet Rostow protestieren Bergarbeiter bereits seit Monaten gegen ausstehende Lohnzahlungen und gefährliche Arbeitsbedingungen in den Schächten. Man sollte diese Proteste nicht überbewerten. Meist bleiben sie lokal. Meist sind es nicht mehr als ein paar hundert Menschen, die protestieren. Fast nie werden diese Proteste politisch, indem sie (mehr) Mitsprache oder politische Veränderungen fordern. Mein persönlicher Eindruck ist aber, dass die Zahl solcher Proteste zunimmt (ich kenne allerdings keine Untersuchungen, die das mit Zahlen belegen könnten). Sollte mein Eindruck stimmen, wäre das ein deutliches Zeichen von wachsender Unzufriedenheit unter der 85-ProzentZustimmung-für-Putin-und-die-Krim-Oberfläche.

Diesen und andere Texte finden Sie auf Jens Siegerts Russlandblog <http://russland.boellblog.org/>.

\section{"Überläufer«.}

\section{Zwei ehemalige Duma-Abgeordnete finden Zuflucht in der Ukraine}

Sergey Medvedev, Berlin

Die Ausreise von zwei ehemaligen Abgeordneten des russischen Parlaments in die Ukraine und ihre kritischen Äußerungen gegenüber dem Regime in Russland haben die Öffentlichkeit überrascht und eine Debatte ausgelöst, ob sie aus politischen Gründen das Land verlassen haben. Denis Woronenkow und Maria Maksakowa-Igenbergs wurden 2011 über die »Kommunistische Partei« und die Partei »Einiges Russland» in die Duma gewählt und zählten in ihren Fraktionen weder zu Spitzenpolitikern, noch zu Regimekritikern. Ihre Hochzeit im März 2015 wurde zum Medienereignis: Sie wurden als »erstes überfraktionelles Ehepaar" gefeiert. Die in München geborene Maksakowa-Igenbergs ist in Russland als Opernsängerin bekannt und kam 
durch die enge Freundschaft mit der Frau des damaligen stellvertretenden Leiters der Präsidialadministration, Wladislaw Surkow, zur Politik. 2013 stimmte sie für das Gesetz gegen »homosexuelle Propaganda«, kritisierte es allerdings ein Jahr später öffentlich als »diskriminierend" und »dem gesunden Menschenverstand widersprechend«. Denis Woronenkow arbeitete nach dem Studium und der Promotion als Jurist beim Militär, bei der Staatsanwaltschaft und bei Gericht. Wie seine ganze Fraktion stimmte Woronenkow 2014 für die Angliederung der Krim an Russland und übte Kritik an der neuen ukrainischen Regierung. Seit Ende 2014 wurde gegen Woronenkow im Rahmen eines Korruptionsverfahrens wegen gesetzeswidriger Enteignung eines Gebäudes im Zentrum Moskaus ermittelt. Die Generalstaatsanwaltschaft bremste aber zunächst die Bemühungen des Ermittlungskomitees. Die Duma weigerte sich bis 2016, die Immunität des Abgeordneten aufzuheben, womit den Ermittlern grünes Licht für Verhöre und eine mögliche Inhaftierung gegeben worden wäre.

Nachdem das Ehepaar 2016 bei den jüngsten Dumawahlen durchfiel, stieg der Druck auf Woronenkow durch das Ermittlungskomitee, sodass sich das Ehepaar entschied, Russland zu verlassen und in die Ukraine zu ziehen. Im Dezember 2016 erhielt Woronenkow die ukrainische Staatsangehörigkeit und machte Angaben im Verfahren wegen Landesverrats gegen den ehemaligen Präsidenten der Ukraine, Wiktor Janukowytsch. Nach der Ausreise in die Ukraine übte der früher regimetreue Duma-Abgeordnete harsche Kritik am Kreml und sagte gegenüber der ukrainischen Online-Zeitung "Zensor.net« u. a.; "die heutige Situation in Russland ist wie in Nazi-Deutschland unter Hitler«. Nach dem brisanten Interview wurde Denis Woronenkow von russischen Ermittlungsbehörden zur Fahndung ausgeschrieben. Maria Maksakowa-Igenbergs, die trotz der Ausreise in die Ukraine ihre Karriere als Opernsängerin in St. Petersburg und Moskau fortsetzen wollte, verlor ihren Arbeitsvertrag. Im Interview für die russische Zeitung »Moskowskij Komsomolez« (mk.ru) weist Woronenkow auf den Druck durch Silowiki hin, dem er nicht mehr habe standhalten können, weswegen er Russland habe verlassen müssen. Viele Blogger zweifeln aber daran, dass es politische Motive bei der Ausreise aus Russland und der raschen Einbürgerung in der Ukraine gegeben hat. Nicht nur staatsnahe Medien und systemtreue Politiker bezeichnen das Ehepaar als Überläufer. Der Kreml-Kritiker Alexej Nawalnyj weist auf eine große Diskrepanz zwischen dem offiziellen Einkommen des Abgeordneten und seinem Besitz von Luxuswohnungen und Autos; Nawalnyj sagt, Denis Woronenkow sei ein typisches Beispiel, wie korrupte Politiker Ideologie als Tarnung benutzten. Andererseits, gibt es im russischen und ukrainischen Internet viele Sympathisanten, die das Vorgehen und die harschen Aussagen Woronenkows trotz seiner möglichen Verwicklung in Korruptionsaffären loben. Das Argument lautet, ehemalige Systempolitiker würden zum Kampf gegen Putin einen bedeutenden Beitrag leisten. Denis Woronenkow ist seit 2012 der vierte Abgeordnete der Staatsduma, der wegen strafrechtlicher Verfolgung Russland verlassen musste.

\section{In diesem Land will ich nicht leben.}

Denis Woronenkow, Duma-Abgeordneter 2011-2016, KPRF

MK.ru: Sie sind ein erwachsener Mensch, der verantwortlich handelt und spricht. Sie werden also wohl verstehen, dass ihre Ausreise und ihre Aussagen in Kiew - das waren ja starke Aussagen - ihre Rückkehr nach Russland ausschließen. D.W.: Ja, absolut. Natürlich ist das eine bewusste Wahl. Sonst würde es keinen Sinn ergeben. In Russland habe ich alles unternommen, um ein Verständnis dafür zu finden, was gesetzeswidrig ist. Diese Sichtweise haben aber auch hochrangige Staatsbeamte (im Gespräch mit mir) geteilt, dass das, was gegen mich vor sich geht $(<$ die Strafverfolgung>) gesetzeswidrig und unfair sind. Niemand will sich damit befassen, verstehen Sie? Ich war nicht in der Lage, alleine gegen diese Gruppe von Menschen zu kämpfen, die im Namen des Staates die Macht usurpiert hat und die Entscheidungen trifft, wer zu bestrafen ist, und wer zu begnadigen. Deswegen habe ich für mich diese Entscheidung getroffen: In diesem Land will ich nicht leben. Lass diese Titanic allein treiben. [...]

MK.ru: Hier wird gesagt, Sie seien vor einem Strafverfahren geflohen, nachdem Sie Immunität des Abgeordneten verloren haben, und der politische Hintergrund sei nur Fassade.

D.W.: Selbstverständlich werden sie auch weiter so reden und mich mit Dreck bewerfen. Erstens: Niemand hat mich jemals verfolgt. Zweitens, ich wurde nicht angeklagt, niemand hat mich vorgeladen. Ich weiß aber, dass in einem "Schlafmodus« ein Verfahren gegen mich fabriziert wurde, damit man mich jeder Zeit belangen könnte. [...] Das war mir gut bewusst, aber ich bin nicht geflohen, ich stand auf keiner Fahndungsliste... [Mittlerweile wird nach Woronenkow russlandweit gefahndet; d. Red.]. [...]

MK.ru: Wie wurden Sie und ihre Frau in der Ukraine empfangen?

D.W:: Sehr gut. Wir sind sehr zufrieden. Es sind sehr gute, freundliche und herzliche Menschen. Wir sehen keine Probleme und, das wichtigste, auch keinen Unterschied... Ich habe immer gesagt, dass Moskau eine böse Stadt ist, und 
ich und Maria haben uns bemüht, bei jeder Gelegenheit zumindest für eine kurze Zeit irgendwohin zu fliegen. So funktioniert es leider dort. Kiew ist aber eine freundliche Stadt. Deswegen fühlen wir uns hier wohl. [...]« Denis Woronenkow am 15. Februar 2017 beim "Moskowskij Komsomolez«; <http://www.mk.ru/ politics/2017/02/15/denis-voronenkov-i-mariya-maksakova-rossiya-poteryaet-mnogikh-izvestnykh-lyudey. html?utm_source=push\&utm_term=push_150217>.

Wenn es nicht die Ukraine wäre, hätte man nicht so mit mir abgerechnet Maria Maksakowa, Opernsängerin und Duma-Abgeordnete 2011-2016, "Einiges Russland"

Meduza: Sind Sie mit der Aussage ihres Mannes einverstanden, der Russland <mit Nazi-Deutschland verglichen hat>? Maksakowa: Sie befinden sich momentan in Riga, obwohl Sie, denke ich, gerne in Moskau leben würden, verstehen Sie? Nun, ich fühle mich aber mit meinem Mann in Kiew wohl. Mir gefällt es hier, hat es immer gefallen. Dass es nun nicht mehr möglich ist, in dem Land zu leben und zu arbeiten, in dem man früher gelebt und gearbeitet hat, ist ein Indikator, inwieweit das Regime seinen Bürgern gegenüber loyal ist. [...]

Meduza: Haben Sie das früher nicht gemerkt? Sie haben die ganze Legislaturperiode in der Duma gearbeitet.

Maksakowa: Das ist ein Prozess. Alles wird immer schlimmer. Vor fünf Jahren ist es nicht so gewesen. Ich habe aus jeglichem Anlass herumgestritten, habe Kommentare auf der Webseite von "Einiges Russland" abgegeben, die dort wahrscheinlich immer noch sind, dass ich mit dem Urteil gegen Pussy Riot nicht einverstanden bin, dass das unschön ist - dass das niemanden schmückt, dass es die administrative Ressource ist, die überall eingedrungen ist. Ich bin bei jedem Anlass, bei jedem Punkt der Agenda immer dagegen gewesen. Ich fand aber, dass man handeln muss... Dort [in der Duma] gibt es ja vernünftige Menschen. [...]«

Maria Maksakowa am 15. Februar 2017 im Interview für Meduza.io; <https://meduza.io/feature/2017/02/15/ esli-by-eto-byla-ne-ukraina-nikto-by-ne-svodil-so-mnoy-schety?>.

\section{Das, was Euch Eure Kinder sagen werden, ist wichtiger, als die Meinung Eurer verdammten Fraktion \\ Michail Kosyrew, TV-Sender "Doschd", Moskau}

"[...] Wie viele solcher Offenbarungen, Bekenntnisse, lichten Momente der Erkenntnis werden wir noch hören!... Wie viel Menschen, die sich dem Regime hingegeben haben und es weidlich ausnutzten, werden noch bereuen und mit Tränen in den Augen sagen: "Wir haben ja nicht gewusst... Was hätten wir tun können?! Wir hatten keine Wahl...«. Erinnert Euch. Erinnert Euch heute daran: Eine Wahl gibt es immer. Die Zeit verrinnt schnell. Das, was Euch Eure Kinder sagen werden, ist wichtiger, als die Meinung Eurer beschissenen Fraktion. Oder Eures Präsidenten." MichailKosyrewam 15. Februar2017 aufFacebook; <https://www.facebook.com/misha.kozyrev/posts/1328957457143289>.

\section{Das Regime Putins ist schwach. Es werden immer wieder Leute fliehen}

Jurij Butosow, Journalist bei "Zensor.net«, Kiew

"In Russland gibt es einfach nur Hysterie, dass Woronenkow und Maksakowa in die Ukraine gegangen sind. Das Interview von Woronenkow, in dem er erbarmungslos das Regime Putins runtermacht und es mit Nazi-Deutschland vergleicht (〈http://censor.net.ua/.../eksdeputat_gosdumy_denis_voronenkov_... ) hat für großes Aufsehen gesorgt; darüber haben alle russischen Medien berichtet, alle Fernsehsender haben Berichte gebracht. Das allgemeine Kommando lautet: kaltmachen und diskreditieren! Selbst bei mir hat heute der Sender "Rossija» angerufen und mich um einen Kommentar zum Interview gebeten, worauf ich höflich geantwortet habe, dass ich einem Sender, der für die Anstiftung zum Krieg in der Ukraine und den Tod von Tausenden meiner Landsleute verantwortlich ist, keine Kommentare geben kann. Ich frage mich, wie haben die das Interview überhaupt gelesen, wenn "Zensor» auf dem Gebiet der Russischen Föderation blockiert ist? Umgehen sie etwa verräterisch die Verbote von [der Medienaufsichtsbehörde] „Roskomnadsor«?

Nun sieht es so aus, als ob Woronenkow ein notorischer Verbrecher ist, ein Schurke, ein hochrangiger Krimineller grad wie der »Große Blonde mit dem schwarzen Schuh«. Wie hat man ihn nur ständig in den Kreml gelassen, in die Administration Putins? Wie konnte er fünf Jahre lang Mitglied des Duma-Ausschusses für Korruptionsbekämpfung sein? Man fragt sich, wie sich die russischen politischen Eliten früher mit Woronenkow und Maksakowa so schön präsentierten? Auf ihrer Hochzeit war die ganze Duma-Spitze, der [Duma-]Vorsitzende und jetzige Chef des Auslandsgeheimdienstes Naryschkin. Maria Maksakowa ist, soweit ich weiß, auf die Parteiliste von "Einiges Russland" durch den Assistenten Putins gelangt, den »Kurator für die Ukraine«, Wladimir Surkow. [...]

Der Fall Woronenkow zeigt anschaulich die tönernen Füße des Putin-Regimes auf. Selbst Abgeordnete der Duma mit Verbindungen und Bekannten auf höchster Ebene glauben nicht an den »Putinismus» und verachten das Feudalsys- 
tem in Russland. Das Regime Putins ist schwach; es werden immer wieder Leute fliehen; Putins Russland ist genauso kurzlebig wie die UdSSR unter Breschnew: verschwindet der Anführer, bricht auch das Kartenhaus zusammen. [...] « Jurij Butusow am 16. Februar 2017 aufFacebook; <https:/www.facebook.com/butusov.yuriy/posts/1551914431515514>.

\section{Einem Korruptionär und Gauner passt jegliche Ideologie}

Alexej Nawalnyj, Blogger und Begründer der »Stiftung für Korruptionsbekämpfung", Moskau

„Der Kerl hat für die Angliederung der Krim gestimmt wie auch mit der ganzen Fraktion die Entsendung von Truppen in die Ukraine unterstützt.

2014 hat er in den Medien Kommentare verbreitet, dass ich hinter Gitter wandern sollte, weil ein »Dieb ins Gefängnis gehört«. Dass ich doch nicht ins Gefängnis kam, heißt, dass die Gesetzgebung Russlands nicht repressiv ist.

2015, als wir für die "Kampagne 20" [Kampagne von Nawalnyj, die sich auf Art. 20 der UN-Antikorruptionskonvention bezieht; d. Red.] alle Abgeordneten beobachtet haben, wurde bei diesem Funktionär, der sich seit 1995 im Staatsdienst befand (u. a. in der Staatsanwaltschaft), Folgendes entdeckt:

- fünf Wohnungen mit einer Gesamtwohnfläche von $1.088 \mathrm{qm}$,

- zwei Garagen

- $\quad$ eine Datscha mit 887 qm, dazu mit einem Funktionsraum von 189 qm

- Die größte Wohnung mit 446,4 qm befindet sich in der Twerskaja-Straße in Moskau und kostet rund 300 Millionen Rubel, [...]

Und all das mit einem offiziellen Einkommen in Höhe von 2,4 Millionen Rubel [im Jahr].

Was war das für ein prächtiger Patriot und Kämpfer gegen die ukrainischen »Banderowzy« [Bandera-Leute]. Er hat bei allen Resolutionen seiner Fraktion zu diesem Thema dafür gestimmt, genauso wie seine Frau Maksakowa von „Einiges Russland«. Im März 2015, einen Monat nach den Ereignissen bei Debalzewo, hat auf der Hochzeit von Woronenkow und Maksakowa der damalige Duma-Vorsitzende Naryschkin gesungen - einer der führenden Heuchler, der über die gekreuzigten Kinder von Slawjansk gequäkt hat. [...]

Das ist ein hervorragendes und belehrendes Beispiel. Einem Korruptionär und Gauner passt jede Ideologie. Heute noch »befreit er den Donbass von den Russophoben« und morgen schon macht er im Kiewer Gericht Aussagen gegen Janukowitsch über dessen Hochverrat. [...]« Alexej Nawalnyj am 27. Januar 2017 auf »navalny.com«; <https://navalny.com/p/5215/>.

\section{Lasst Woronenkow und Maksakowa in Ruhe!}

Alfred Koch, Politiker, Rosenheim (Bayern)

"Liebe Wächter der sauberen Reihen! Lasst Woronenkow und Maksakowa in Ruhe!

Eine einfache Kalkulation zeigt, dass ihr Wechsel auf die Seite der Putin-Feinde dieser (Eurer?) Seite ein Plus von zwei Personen ergibt, aber auch ein Minus von zwei für die Seite Putins.

Also ein Plus von vier auf ein Mal. Und was für eins: mit Geldern, Connections und Informationen. Oder wollt Ihr etwa nicht, dass es weniger Anhänger Putins und mehr von seinen Gegnern gibt?

Wie seht Ihr sonst dieses Coming-Out? [...]«

Alfred Koch am 14. Februar 2017 aufFacebook; <https://www.facebook.com/koch.kokh.haus/posts/1673153636315172>

\section{Verräter mag man nirgendwo. Das schöne Kiew ist keine Ausnahme}

Sergej Newerow, stellv. Duma-Vorsitzender, Partei "Einiges Russland“, Moskau

"Das will einem nur schwer in den Kopf: Wie kann es sein, dass diese Menschen gestern noch Abgeordnete waren und versuchten, wieder in die Duma einzuziehen? Nein, mir kommt immer wieder der Gedanke, dass das Pärchen in den Kerkern des SBU [Sicherheitsdienst der Ukraine] gefoltert wird: Denis werden Nadeln unter die Nägel gestoßen und der Opernsängerin wird mit damit gedroht, dass ihr flüssiges Blei in die Kehle gegossen wird, oder mit dem Tod ihres "ersten überfraktionellen Kindes«. Sollen wir vielleicht Spezialkräfte in die Ukraine schicken, um sie zu retten? Ich fürchte nur, dass es der Ausdruck der falschen Natur von Maria Maksakowa-Igenbergs und ihres neuen Mannes ist. Es freut einen, dass sie nicht auf den Abgeordneten-Listen der Duma der 7. Wahlperiode stehen. Verräter mag man nirgendwo; das schöne Kiew ist keine Ausnahme«. Sergej Newerow am 16. Februar 2017 auf Facebook; <https://www.facebook.com/permalink. php?story_fbid=599384606921933\&id=100005511976455> 


\section{Februar - 2. März 2017}

\begin{tabular}{|c|c|}
\hline 17.02 .2017 & $\begin{array}{l}\text { Der britische Sender BBC strahlt eine Dokumentation über russische Hooligans mit dem Titel »Russia’s Hoo- } \\
\text { ligans Army« aus. Darin drohen gewaltbereite Fans in Interviews mit den Filmemachern, die englischen Fans } \\
\text { während der Fußballweltmeisterschaft } 2018 \text { in Russland zu attackieren. }\end{array}$ \\
\hline 17.02.2017 & $\begin{array}{l}\text { Im Hotel Bayerischer Hof beginnt die dreitägige 53. Münchner Sicherheitskonferenz, auf der Politiker und Fach- } \\
\text { leute über globale Sicherheits- und Verteidigungsfragen beraten. Thema ist unter anderem die Zukunft der Nato, } \\
\text { die EU sowie die Kriege in Syrien und in der Ukraine. }\end{array}$ \\
\hline 18.02 .2017 & $\begin{array}{l}\text { Präsident Wladimir Putin unterzeichnet einen Erlass, dem zufolge Russland Dokumente anerkennt, die von den } \\
\text { Behörden der international nicht anerkannten »Volksrepubliken Donezk« und »Volksrepublik Lugansk« ausge- } \\
\text { stellt wurden. Gemäß dem Erlass können Personen mit solchen Dokumenten nun unter Vorlage ihrer Ausweis- } \\
\text { dokumente ohne Visum nach Russland einreisen. }\end{array}$ \\
\hline 19.02 .2017 & $\begin{array}{l}\text { Der Koordinator der Organisation »Offenes Russland«, Vladimir Kara-Murza, wird aus dem Krankenhaus ent- } \\
\text { lassen, in das er mit Symptomen einer schweren Vergiftung Anfang Februar eingeliefert worden war. Laut sei- } \\
\text { nem Anwalt wird er die medizinische Behandlung im Ausland fortsetzen. }\end{array}$ \\
\hline 19.02 .2017 & $\begin{array}{l}\text { Britische und US-amerikanische Geheimdienste haben laut Berichten der britischen Zeitung »Telegraph« Beweise } \\
\text { für eine russische Beteiligung am vereitelten Umsturzversuch in Montenegro im Oktober 2016. Russland weist } \\
\text { die Vorwürfe zurück. Mehrere Serben stehen in Montenegro unter Verdacht, am Wahltag ein Attentat auf den } \\
\text { damaligen Ministerpräsidenten Milo Dukanović sowie einen Putsch geplant zu haben. }\end{array}$ \\
\hline 20.02 .2017 & $\begin{array}{l}\text { as russische Verteidigungsministerium teilt mit, dass am 16. Februar bei der Explosion eine Mine vier russi- } \\
\text { he Soldaten in Syrien getötet und zwei weitere verletzt wurden. }\end{array}$ \\
\hline 20.02 .2017 & $\begin{array}{l}\text { äsident Wladimir Putin ordnet an, dass die russische Zentralregierung zusammen mit den Regionen ein Sys- } \\
\text { m zur Suizid-Prävention unter Jugendlichen einrichten soll. }\end{array}$ \\
\hline 20.02 .2017 & $\begin{array}{l}\text { Der langjährige ständige Botschafter Russlands bei den Vereinten Nationen, Witalij Tschurkin, stirbt in New } \\
\text { York einen Tag vor seinem } 65 \text {. Geburtstag. Laut Informationen aus US-Regierungskreisen erlag Tschurkin einem } \\
\text { Herzinfarkt. }\end{array}$ \\
\hline 21.02 .2017 & $\begin{array}{l}\text { er ehemalige Duma-Abgeordnete Dmitrij Gudkow gibt auf einer Pressekonferenz offiziell seine Kandidatur bei } \\
\text { n Moskauer Bürgermeisterwahlen bekannt. }\end{array}$ \\
\hline 21.02 .2017 & $\begin{array}{l}\text { n Mikrorayon Kamenka der Stadt Simferopol nimmt die Polizei den krimtatarischen Aktivisten Marlen Musta- } \\
\text { jew fest und durchsucht dessen Haus. Als Krimtataren dagegen protestieren, werden } 20 \text { Personen festgenommen. }\end{array}$ \\
\hline 21.02 .2017 & $\begin{array}{l}\text { ie russische Regierung vergibt insgesamt 10,3 Milliarden Rubel an } 21 \text { führende russische Universitäten zur } \\
\text { ärkung ihrer internationalen Konkurrenzfähigkeit. Ziel sei, dass mindestens fünf Universitäten bis } 2020 \mathrm{zu} \\
\text { en hundert besten der Welt zählen. }\end{array}$ \\
\hline 22.02 .2017 & $\begin{array}{l}\text { Das Oberste Gericht hebt die Haftstrafe des Oppositionellen Ildar Dadin auf. Dadin war die erste Person, die } \\
\text { nach } ₫ 212.1 \text { des Strafgesetzbuches wegen »mehrfacher Verletzung des Demonstrationsrechts« zu einer Haftstrafe } \\
\text { verurteilt worden war. Die Entscheidung des Obersten Gerichts folgt dem Beschluss des Verfassungsgerichts von } \\
\text { Anfang Februar, das den Strafrechtsparagraph zwar für verfassungsgemäß einschätzte, allerdings nur wenn von } \\
\text { einem Demonstranten eine konkrete Gefahr für die Öffentlichkeit ausgeht. }\end{array}$ \\
\hline 22.02 .2017 & $\begin{array}{l}\text { Das Außenministerium richtet auf seiner Internetseite eine Rubrik für Fake News ein, auf der Falschmeldungen } \\
\text { über Russland zusammengetragen und entkräftet werden sollen. }\end{array}$ \\
\hline 22.02 .2017 & $\begin{array}{l}\text { Verteidigungsminister Sergej Schojgu bestätigt während einer Sitzung der Staatsduma, dass eine neue Spezial- } \\
\text { einheit für IT-Kriegsführung geschaffen worden sei. Der Vorsitzende des Verteidigungsausschusses des russi- } \\
\text { schen Parlaments, Wladimir Schamanow, erklärte, Zweck der Einheit seien die nationale Verteidigung und der } \\
\text { Kampf in der Informations-Sphäre. }\end{array}$ \\
\hline 22.02 .2017 & $\begin{array}{l}\text { Verteidigungsminister Sergej Schojgu berichtet, dass ein Modell des Berliner Reichstags im Militär-Freizeitpark } \\
\text { Kubinka westlich von Moskau gebaut werden soll. Im Park»Patriot« könnten somit militärbegeisterte Jugendli- } \\
\text { che (etwa der »unarmija») trainieren, wie man ein Gebäude stürmt. Darüber hinaus sollen weitere Schauplätze } \\
\text { des Zweiten Weltkrieges nachgebaut werden. }\end{array}$ \\
\hline
\end{tabular}




\begin{tabular}{|c|c|}
\hline 23.02.2017 & $\begin{array}{l}\text { In Genf beginnt unter der Schirmherrschaft der UNO eine neue Runde der innersyrischen Friedensverhandlun- } \\
\text { gen. UN-Vermittler Staffan de Mistura empfängt den Leiter der Regierungsdelegation, Syriens UN-Botschafter } \\
\text { Baschar al-Dschafari, sowie eine kleine Delegation der Opposition. Außerdem reisen Diplomaten und Experten } \\
\text { der USA, der Türkei und Russlands als Beobachter an. Inhaltlich geht es um die die Bildung einer Übergangsre- } \\
\text { gierung, die Ausarbeitung einer Verfassung und die Abhaltung freier und fairer Wahlen. Die Friedensverhand- } \\
\text { lungen zwischen der Regierung und Opposition werden von einer Anschlagsserie in der zentralsyrischen Stadt } \\
\text { Homs überschattet. }\end{array}$ \\
\hline 25.02.2017 & Mehr als 500 Personen demonstrieren in Novosibirsk gegen die Tariferhöhungen für kommunale Dienstleistungen. \\
\hline 26.02 .2017 & $\begin{array}{l}\text { Zwei Jahre nach dem Tod des Oppositionspolitikers Boris Nemzow erinnern Tausende Menschen in Moskau mit } \\
\text { einem Gedenkmarsch an Nemzows Ermordung unweit des Kreml. }\end{array}$ \\
\hline 27.02 .2017 & $\begin{array}{l}\text { Ministerpräsident Dmitrij Medwedew entlässt den seit } 2014 \text { amtierenden Stellvertretenden Minister für wirt- } \\
\text { schaftliche Entwicklung, Aleksej Wedew, auf dessen eigenen Wunsch. }\end{array}$ \\
\hline 27.02.2017 & $\begin{array}{l}\text { Der Inlandsgeheimdienst (FSB) nimmt im Gebiet Samara einen mutmaßlichen Anhänger der Terrormiliz »Isla- } \\
\text { mischer Staat« fest. Der 19-jährige russische Staatsbürger wird verdächtigt, einen Anschlag auf Sicherheitskräfte } \\
\text { geplant zu haben. }\end{array}$ \\
\hline 28.2.2017 & $\begin{array}{l}\text { Im UN-Sicherheitsrat verhindern Russland und China mit einem Veto eine von den USA, Frankreich und } \\
\text { Großbritannien eingebrachte Resolution, die Strafmaßnahmen gegen das syrische Regime wegen des Einsatzes } \\
\text { von Giftgas vorsah. }\end{array}$ \\
\hline 28.2.2017 & $\begin{array}{l}\text { Das Strafermittlungskomitee lädt Wladimir Osetschkin, den Gründer des sozialen Netzwerks »Gulagu.net«, zum } \\
\text { Verhör vor. Bei Soja Swetowa, einem ehemaligen Mitglied der Moskauer Gesellschaftlichen Beobachtungskom- } \\
\text { mission (ONK) führen Sicherheitsorgane eine Hausdurchsuchung durch. Das Vorgehen steht im Zusammen- } \\
\text { hang mit dem Vorgehen gegen Jelena Abdullajewa, die Projektkoordinatorin der ONK. }\end{array}$ \\
\hline 1.3 .2017 & $\begin{array}{l}\text { Das Neunte Berufungsgericht hebt ein Urteil der Vorinstanz auf, in dem das Verlagshaus RBK im Dezember } \\
\text { wegen Rufschädigung des staatlichen Mineralölkonzerns "Rosneft« zu einer Geldstrafe von } 390.000 \text { Rubel ver- } \\
\text { urteilt worden war. Das Gericht erlässt aber an RBK die Auflage, eine Gegendarstellung zu den Informationen } \\
\text { zu veröffentlichen, die den Ruf von Igor Setschin und Rosneft geschadet hätten. }\end{array}$ \\
\hline 2.3.2017 & $\begin{array}{l}\text { Die Washington Post berichtet, dass der US-Justizminister Jeff Sessions zwei Mal mit dem russischen Botschaf- } \\
\text { ter in den USA gesprochen und das dem Senat verschwiegen habe. Die Meldung wird vom US-Justizministe- } \\
\text { rium bestätigt. }\end{array}$ \\
\hline 2.3.2017 & $\begin{array}{l}\text { Die Stiftung zur Korruptionsbekämpfung von Aleksej Nawalnyj veröffentlicht Recherchen und einen Film über } \\
\text { die Residenzen und Vermögenswerte von Ministerpräsident Dmitrij Medvedev < https://dimon.navalny.com/>. }\end{array}$ \\
\hline 2.3.2017 & $\begin{array}{l}\text { Das Komitee für Bürgerliche Initiativen (KGI) stellen ihren Bericht zur sozialen und politischen Lage in den } \\
\text { Regionen Russlands vor, in dem die sozioökonomischen und politischen Risiken und Spannungen sowie die Pro- } \\
\text { testaktivitäten in der zweiten Jahreshälfte } 2016 \text { analysiert und besonders risikoreiche Regionen herausstellt wer- } \\
\text { den }<\text { https://komitetgi.ru/news/news/3153/>. }\end{array}$ \\
\hline
\end{tabular}

Sie können die gesamte Chronik seit 1964 auch auf <http://www.laender-analysen.de/russland/> unter dem Link »Chronik«lesen.

Herausgeber: Forschungsstelle Osteuropa an der Universität Bremen, Zentrum für Osteuropa- und internationale Studien (ZOiS) gGmbH und Deutsche Gesellschaft für Osteuropakunde e.V.

Die Meinungen, die in den Russland-Analysen geäußert werden, geben ausschließlich die Auffassung der Autoren wieder. Abdruck und sonstige publizistische Nutzung sind nach Rücksprache mit der Redaktion gestattet. Redaktion: Hans-Henning Schröder (verantwortlich), Julia Glathe Sprachredaktion: Hartmut Schröder Satz: Matthias Neumann

Russland-Analysen-Layout: Cengiz Kibaroglu, Matthias Neumann und Michael Clemens Alle Ausgaben der Russland-Analysen sind mit Themen- und Autorenindex archiviert unter www.laender-analysen.de Die Russland-Analysen werden im Rahmen eines Lizenzvertrages in das Internetangebot der Bundeszentrale für politische Bildung (www.bpb.de) aufgenommen. ISSN 1613-3390 @ 2017 by Forschungsstelle Osteuropa an der Universität Bremen, Zentrum für Osteuropa- und internationale Studien (Z0iS) gGmbH und Deutsche Gesellschaft für Osteuropakunde e.V. Forschungsstelle Osteuropa • Länder-Analysen • Klagenfurter Str. 8 • 28359 Bremen • Telefon: +49 421-218-69600 • Telefax: + 49 421-218-69607 e-mail: Iaender-analysen@uni-bremen.de•Internet-Adresse: http://www.laender-analysen.de/russland/ 

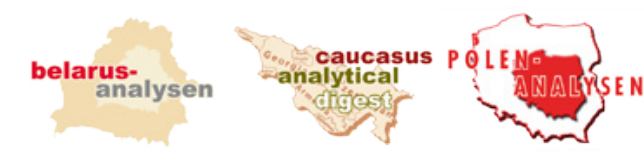

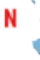

\section{Kostenlose E-Mail-Dienste der Forschungsstelle Osteuropa und ihrer Partner auf www.laender-analysen.de}

Die Länder-Analysen bieten regelmäßig im kostenlosen Abonnement kompetente Einschätzungen aktueller politischer, wirtschaftlicher, sozialer und kultureller Entwicklungen in Ostmitteleuropa und der GUS. Sie machen das Wissen, über das die wissenschaftliche Forschung in reichem Maße verfügt, für Politik, Wirtschaft, Medien und die interessierte Öffentlichkeit verfügbar. Autoren sind internationale Fachwissenschaftler und Experten. Die Redaktionen der Länder-Analysen bestehen aus Wissenschaftlern mit langjähriger Forschungserfahrung.

Die einzelnen Länder-Analysen werden von der Forschungsstelle Osteuropa an der Universität Bremen und der Deutschen Gesellschaft für Osteuropakunde herausgegeben. Partner der deutschsprachigen Analysen zur postsowjetischen Region ist das Zentrum für Osteuropa- und internationale Studien (ZOiS) gGmbH, Partner der Polen-Analysen ist das Deutsche Polen-Institut. Partner der englischsprachigen Analysen ist die ETH Zürich.

Die Länder-Analysen bieten regelmäßig Kurzanalysen zu aktuellen Themen, ergänzt um Grafiken und Tabellen sowie Dokumentationen. Zusätzlich gibt es eine Chronik aktueller Ereignisse. Alle Länder-Analysen sind auch mit Archiv und Indizes online verfügbar unter <www.laender-analysen.de $>$.

\section{Belarus-Analysen}

Erscheinungsweise: zweimonatlich

Abonnement unter: <http://www.laender-analysen.de/belarus/>

\section{Caucasus Analytical Digest}

In englischer Sprache. Erscheinungsweise: monatlich

Abonnement unter: <http://www.css.ethz.ch/en/publications/cad.html>

\section{Polen-Analysen}

Erscheinungsweise: zweimal monatlich

Abonnement unter: <http://www.deutsches-polen-institut.de/newsletter/polen-analysen/>

Auch als App für Android ${ }^{\mathrm{TM}}$ (ab Januar 2016) kostenlos auf Google Play ${ }^{\mathrm{TM}}$.

\section{Russland-Analysen}

Erscheinungsweise: zweiwöchentlich

Abonnement unter: <http://www.laender-analysen.de/russland/>

Auch als App für Android (ab Januar 2016) kostenlos auf Google Play.

\section{Russian Analytical Digest}

In englischer Sprache. Erscheinungsweise: zweimal monatlich

Abonnement unter: <http://www.css.ethz.ch/en/publications/rad.html>

\section{Ukraine-Analysen}

Erscheinungsweise: zweimal monatlich

Abonnement unter: <http://www.laender-analysen.de/ukraine/>

Auch als App für Android (ab Januar 2016) kostenlos auf Google Play.

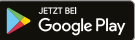

\section{Zentralasien-Analysen}

Erscheinungsweise: monatlich

Abonnement unter: <http://www.laender-analysen.de/zentralasien/>

Auch als App für Android (ab Januar 2016) kostenlos auf Google Play.

\section{Bibliographische Dienste}

Die Bibliographien informieren über englisch- und deutschsprachige wissenschaftliche Neuerscheinungen zu Belarus, Russland, Ukraine sowie zu den zentralasiatischen und kaukasischen Staaten. Erfasst werden jeweils die Themenbereiche Politik, Außenpolitik, Wirtschaft und Soziales.

Erscheinungsweise: viermal jährlich

Abonnement unter: <http://www.laender-analysen.de/bibliographies $>$ 